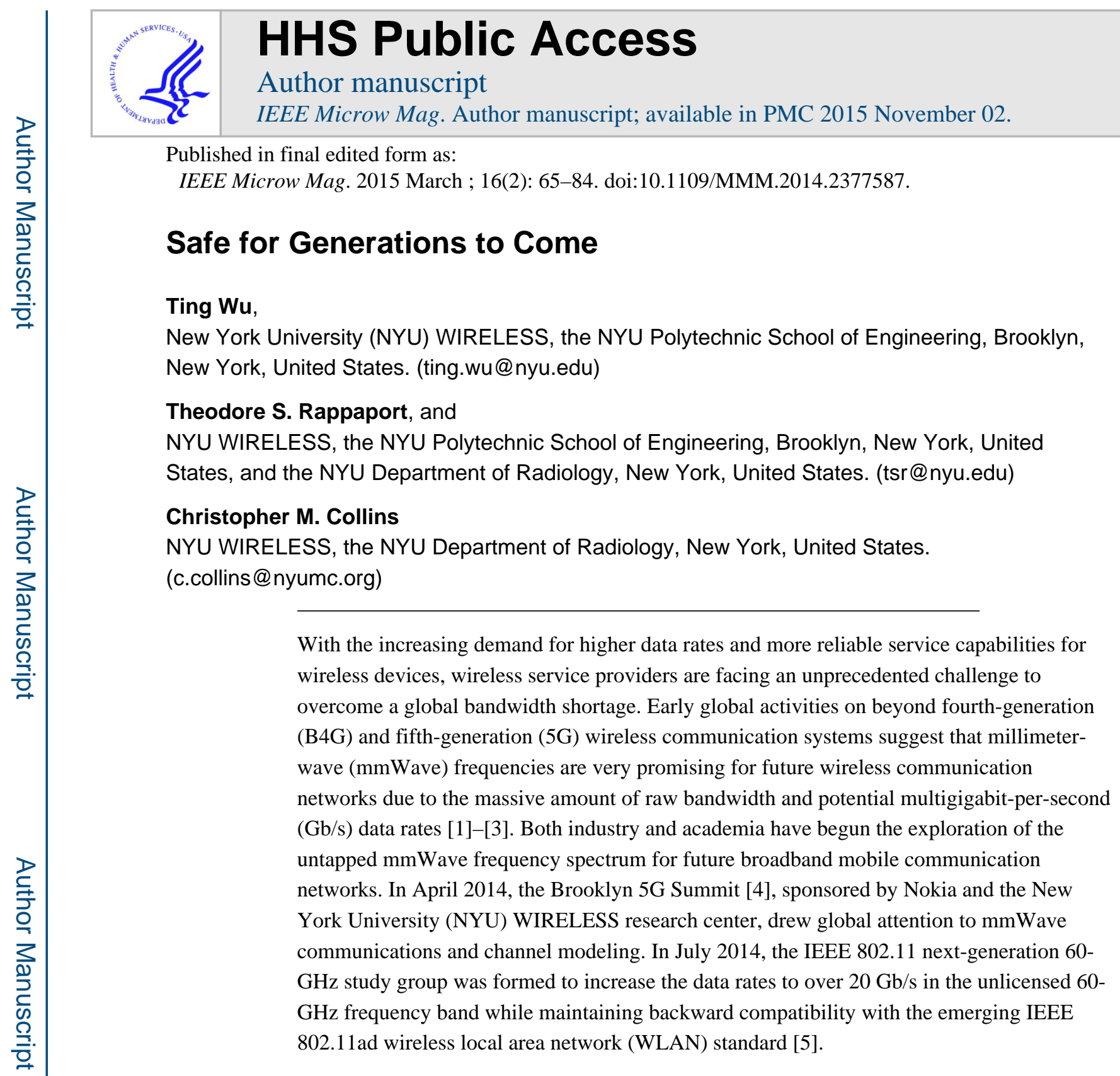




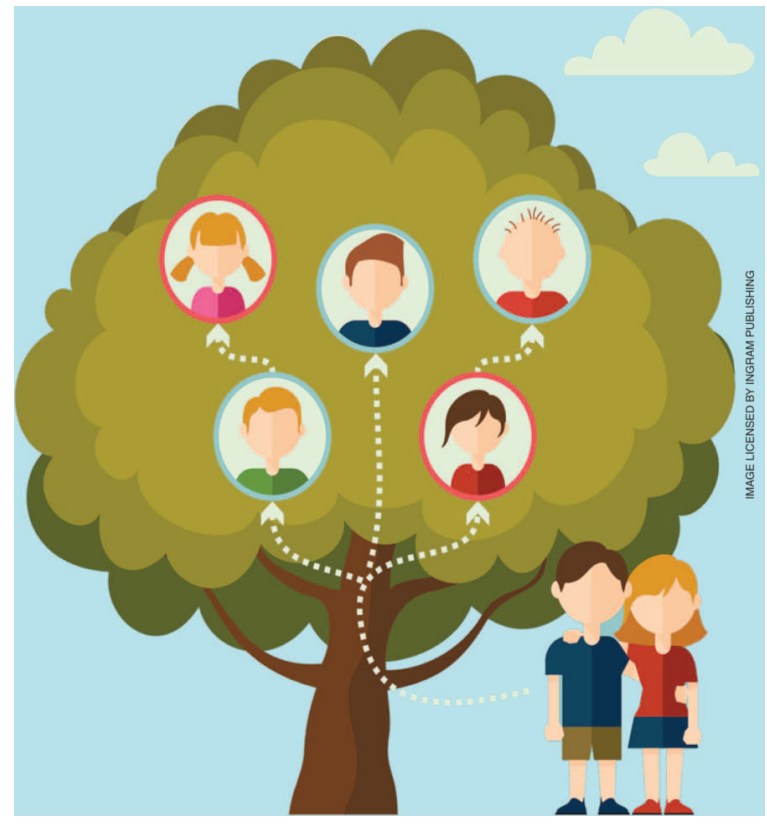

The increasing investigations of mmWave applications and technologies have stimulated interest in, as well as concerns about, biological safety at mmWave frequencies. Biological study of mmWaves is needed to ensure safety and to enhance our fundamental understanding of the interactions of mmWave systems with the human body. Moreover, from a safety point of view, research on mmWave biological effects is also necessary for accurately evaluating the potential health hazards related to mmWave exposure and for developing and updating safety standards for the mmWave regime. It is important to note that many governments presently rely on regulations that were developed before the year 2000 , well before the rapid growth of wireless communications and low-cost mmWave devices. Thus, new approaches and additional data are needed to mitigate any unnecessary anxiety of the general public as new mmWave technologies evolve, while ensuring the safe use of future mmWave systems and devices.

Most of this article is dedicated to discussions of the well-accepted and well-understood thermal heating of tissues. At mmWave frequencies, this pertains primarily to the skin and eyes as the small penetration depths prohibit propagation of energy further into the body. Although the presence of various nonthermal effects has been reported, discussed, disputed, and refuted for decades even at mmWave frequencies [6]-[8], the IEEE International Committee on Electromagnetic Safety states that for frequencies from $3 \mathrm{kHz}$ to $300 \mathrm{GHz}$ : "a review of the extensive literature on radio-frequency (RF) biological effects, consisting of well over 1,300 primary peer-reviewed publications published as early as 1950, reveals no adverse health effects that are not thermally related" and "no reproducible low-level (nonthermal) effect that would occur even under extreme environmental exposures...harmful effects are and will be due to excessive absorption of energy, resulting in heating that can result in a detrimentally elevated temperature," such that at radiation levels low enough to avoid excessive heating it should be harmless [9], [10]. The use of low-level (less than $1 \mu \mathrm{W} / \mathrm{cm}^{2}$ ) radiation in mmWave airport security scanners throughout the world on thousands of travelers is performed daily under the widely accepted view that the only 
potential direct biological effect of the nonionizing radiation in this band is heating [11]. On the extreme of high-intensity human exposures, the U.S. government has investigated the use of very strong mmWave beams to cause heating of skin for the potential purpose of nonlethal crowd control and observed only effects that can be explained by thermal mechanisms [12].

Nonetheless, given the importance of this topic to the wireless industry, we present this literature survey representing the most recent available results related to the biological effects of mmWave exposure, from the well-understood and well-accepted effects of thermal heating to recent reports of nonthermal effects and the attempt to motivate further discussion and research for appropriate emission standards.

\section{Fundamentals of mmWave Radiation}

\section{Nonionizing Characteristic of mmWave Radiation}

The mmWave band is the part of the RF spectrum between 30 and $300 \mathrm{GHz}$ that corresponds to a free space wavelength ranging from 10 to $1 \mathrm{~mm}$.

While electromagnetic energy in this regime is often described in terms of traveling waves [13], it can also be described as having a particle-like nature [14]. These particle-like components of electromagnetic waves are called "photons." Each photon has an energy level given by [14]

$$
E=h f=\frac{h c}{\lambda},
$$

where $h$ is Planck's constant $\left(h=6.626 \times 10^{-34} \mathrm{~J} \cdot \mathrm{s}\right.$ or $\left.4.135 \times 10^{-15} \mathrm{eV} \cdot \mathrm{s}\right), c$ is the speed of light $\left(3 \times 10^{8} \mathrm{~m} / \mathrm{s}\right)$, and $\lambda$ is the wavelength $(\mathrm{m})$ of the radiated signal. The photon energy of mmWaves ranges from 0.1 to $1.2 \mathrm{meV}$. Unlike ionizing radiation (ultraviolet, $\mathrm{X}$-ray, and gamma radiation), which has been linked to cancer due to the displacement of electrons during exposure [15], mmWave radiation is nonionizing because the photon energy is not nearly sufficient to remove an electron from an atom or a molecule (typically $12 \mathrm{eV}$ is required) [17]. Thus, at mmWave frequencies, the photon energy is more than four orders of magnitude weaker than ionizing radiation and is thus not capable of displacing electrons, which disrupts molecular bonds; this disruption is linked to cancer [15]. Instead, heating is the major biological effect caused by the absorption of electromagnetic mmWave energy by tissues, cells, and biological fluids. For example, in the spectrum of energy emitted by the sun, it is the ultraviolet light (with shorter wavelengths and higher energy photons than visible light) that is associated with skin cancer, while the energy emitted with longer wavelengths and lower-energy photons than visible light (including the infrared energy) is associated only with warmth in terms of biological effects. Communication systems must comply with government exposure guidelines, such as [16] and [17], to prevent any adverse health effects related to these thermal effects. If any nonthermal bioeffects related to mmWave radiation are determined conclusively to be harmful to the human body, they should be considered and carefully studied for any update of future mmWave radiation guidelines. 


\section{Dosimetric Quantities to Measure RF Exposure}

When measuring the intensity and effects of RF exposure, three major dosimetric quantities are commonly studied [9], [10]: the specific absorption rate (SAR), plane-wave equivalent power density, and the steady-state and/or transient temperature.

\section{SAR}

The SAR is a quantitative measure of RF power absorbed in a living body. It is a function of the distributions of the electric field and tissue properties (mass density and conductivity) throughout the exposed tissue [10]

$$
S A R=\frac{P_{\text {diss }}}{m}=\frac{\sigma|E|^{2}}{\rho},
$$

where $P$ diss $(\mathrm{W})$ is the radiation power dissipated in the tissue, $m$ is the tissue mass $(\mathrm{kg})$ under exposure, $\sigma$ is the conductivity [in Siemens/meter $(\mathrm{S} / \mathrm{m})$ ] of the tissue, $\rho$ is the tissue mass density $\left(\mathrm{kg} / \mathrm{m}^{3}\right)$, and $E$ is the root mean square (rms) value of the electric-field strength $(\mathrm{V} / \mathrm{m})$ dissipated in the tissue. The international system of units (SI) of SAR is Watts per kilogram, thus indicating that SAR represents a power level per body mass (e.g., power is dissipated throughout a volume of tissue). Note that in (2), $E, \sigma$, and $\rho$ are all functions of the position within the tissue under exposure. For example, the SAR at the surface of the exposed tissue will be different from the SAR deep within the tissue [18], as shown in the "mmWave Effects on Skin" section. In an unperfused homogenous material initially at equilibrium with the environment, just after exposure to SAR $(t \rightarrow 0)$, is initiated such that thermal conduction has not begun to have a significant effect

$$
S A R \cong \frac{c \Delta T}{\Delta t},
$$

where $c$ is the specific heat capacity $\left(\mathrm{J} / \mathrm{kg} /{ }^{\circ} \mathrm{C}\right)$ of the tissue, $\Delta T$ is the change in temperature $\left({ }^{\circ} \mathrm{C}\right)$ within the tissue, and $\Delta t$ is the duration of exposure (s). The relationship between SAR and temperature in more realistic representations of living tissue will be discussed later.

\section{Plane-Wave Equivalent Power Density}

In the far field of a transmitting antenna, where the electric-field vector, the magnetic-field vector, and the direction of propagation can be considered to be mutually orthogonal (planewave condition), the power density (PD) can be written as follows [10], [19]:

$$
P D=\frac{\left|E_{i}\right|^{2}}{\eta}=\eta\left|H_{i}\right|^{2}
$$

where $E_{i}(\mathrm{~V} / \mathrm{m})$ and $H_{i}(\mathrm{~A} / \mathrm{m})$ are the rms values of the electric- and magnetic-field strengths incident on the surface of the tissue, and $\eta$ is the wave impedance ( $377 \Omega$ in free space). The SI unit of PD is watts per square meter. Note that this is a power per surface area metric.

In the near field of a transmitting antenna, the term "far-field equivalent" or "plane-wave equivalent" PD is often used to indicate a quantity calculated using the near-field values of 
$E_{i}(\mathrm{~V} / \mathrm{m})$ or $H_{i}(\mathrm{~A} / \mathrm{m})$ "as if they were obtained in the far field" [20]. In the near field of an antenna, however, the ratio of $E$ to $H$, and thus even the impedance of free space, $\eta$, are functions of position and are different than in the far field. Because mmWave handheld devices with dozens of antennas used close to the head or face will result in near-field, not far-field, radiation, caution is warranted in applying existing regulatory guidelines in evaluating the safety of evolving handsets (discussed further in the "Standards for mmWave Exposures" section).

The expression for the PD radiated by a transmit antenna at a far-field distance $d$ is

$$
P D_{\text {far }- \text { field }}=\frac{G_{t} P_{t}}{4 \pi d^{2}},
$$

where $G_{t}$ is the transmit antenna gain in linear scale, $P_{t}(\mathrm{~W})$ is the total power fed into the antenna, and $d(\mathrm{~m})$ is the distance from the radiation source. Note that the far-field distance (Fraunhofer distance) for a directional mmWave antenna is determined by the largest dimension of the antenna $(D)$ and the wavelength $(\lambda)$ where the far-field assumption is accurate for distances greater than $d_{\text {far_field }}=2 D^{2} / \lambda$ [19]. Unlike evaluations of SAR or temperature, evaluations based on PD do not rely on knowledge of the distribution of fields or power absorption in the tissues but only on the density of power traveling toward the tissue. Hence, PD is not likely to be as useful as SAR or temperature for assessing safety in mmWave devices, especially in the near field.

\section{Steady-State and/or Transient Temperature}

Steady-state and/or transient temperature of the tissues/samples under study is particularly important in evaluating the effect of medium- and high-power radiation, where skin can be heated rapidly. The main deleterious effect of electromagnetic energy absorption is heating at both microwave and mmWave frequencies. Cases of accidental overexposure have been reported in the literature from faulty microwave ovens operating at 2,450 MHz [21], [22]. In controlled exposures to very high-power (PD on the order of $10,000 \mathrm{~W} / \mathrm{m}^{2}$ at $95 \mathrm{GHz}$ with exposures of only a few seconds) mmWave-based nonlethal crowd control technology, over 11,000 exposures resulted in only eight second-degree burns. In all of these cases, the subjects recovered fully [12]. Even at these high exposure levels, it was expected that the human reflex reaction would shield the eyes from damage and that no long-term or carcinogenic effects would be seen [12]. Skin depth (corresponding to $1 / \mathrm{e}^{2}$ or $13.5 \%$ of the PD transmitted across the skin surface) is well understood to decrease with the increase of radiation frequencies [13]. For ultrahigh frequency (UHF)/microwave frequencies and below, heating due to RF radiation goes deeper into the tissue. However, at mmWave frequencies, most of the energy is absorbed within the first few millimeters of human skin, for example, $0.41 \mathrm{~mm}$ at $42.25 \mathrm{GHz}$ [23]. Thus, thermal injury due to overexposure of mmWave is expected to produce superficial burns like those produced when a person touches hot objects or flames. In other words, mmWave-induced burns will likely generate blistering and local inflammatory responses that are similar to conventional burns rather than the deep tissue thermal injury characteristic of overexposure at microwave frequencies. 
Humans can detect a sense of warmth on the skin due to mmWave-induced temperature elevations of less than $0.1{ }^{\circ} \mathrm{C}$ [24], but as discussed in the "Standards for mmWave Exposures" section, temperature changes in the skin in excess of $1{ }^{\circ} \mathrm{C}$ are viewed to be safe [25]-[28]. The normal temperature of the outer surface of the skin is typically $30-35^{\circ} \mathrm{C}$ or a few degrees lower than core body temperature (typically $37^{\circ} \mathrm{C}$ ). The threshold for pain detection by humans is $43-45^{\circ} \mathrm{C}$. Various levels of thermal injuries may occur above $45{ }^{\circ} \mathrm{C}$ for different temporal durations, as detailed in [27], or for a recent model for damage gaining acceptance in the hyperthermia and ablation community [28], above $43{ }^{\circ} \mathrm{C}$ depending on the duration.

\section{Standards for mmWave Exposures}

\section{Global Exposure Limits}

To protect humans against established adverse health effects, mmWave radiation should comply with safety standards. Five different governmental RF far-field PD exposure limits for whole-body exposure (where the incident power is averaged over the whole body) for the general public are listed in Table 1. It can be seen that the exposure limits in Russia, China, Switzerland, and Italy are two orders of magnitude lower than those in the United States and most Western European countries. These exposure limits are developed either from science-based or precautionary reasoning, as shown in Table 1 and discussed in [29] and [30].

Science-based limits were based on studies that identified potentially hazardous effects, mostly through tests with animals and humans. The exposure guidelines used in the United Stated [the U.S. Federal Communications Commission (FCC)], most European countries [the International Commission on Non-Ionizing Radiation Protection (ICNIRP)], Russia, and China are developed based on science-based reasoning. The exposure guidelines developed by the FCC and ICNIRP, principally designed to protect against adverse thermal effects, were largely based on studies of short-term exposures to animals at high power levels, as clearly pointed out in the extensive documentation of the standards [16] and [17]. However, Russian and Chinese limits are well below any thermally significant levels. These limits imply that long-term exposure at levels below FCC and ICNIRP limits may result in adverse nonthermal health effects. One can speculate that these more conservative regulations stem from nonspecific health problems (such as headaches, fatigue, irritability, sleep disorders, and dizziness) that were reported in the medical literature from Russia and China based on low-level exposure studies [31]. However, many of those studies lacked basic information, such as the frequency and intensity of exposure, and the diagnostic criteria is vague; thus, these studies cannot be carefully evaluated or relied on by other researchers.

The precautionary limits adopted by Switzerland and Italy were set at the lowest levels that were technically and economically feasible to address public concern about the potential adverse effects of broadcast transmitters and wireless base stations in the early 2000s. They were "specifically intended to minimize the yet unknown risks" [30] of RF electromagnetic fields (EMFs). Although the precautionary limits of Switzerland and Italy are greater than $\mathrm{RF}$ exposure levels resulting from typical wireless base station antennas mounted at 
conventional heights on towers (see the last entry in Table 1), these guidelines make it difficult to locate base station antennas on apartment buildings and other low structures near people. Interestingly, the Swiss limits do not apply to wireless handsets, which expose the user to a far higher level of RF energy than wireless base stations and also provide exemptions for medical or industrial exposures.

The harmonization of RF exposure limits around the world has long been desired among standards-setting committees. The importance of harmonization lies in that it can provide a consistent set of validated and approved exposure limits to protect all people worldwide. Also, harmonization makes it easier for the wireless industry to serve a worldwide market. Moreover, it can help reduce the political controversy or public fear that is sometimes irrationally applied to RF radiation. Harmonization is one major goal of the World Health Organization's EMF Project [37]. Currently, 54 participating countries and eight international organizations are involved in the international EMF Project, providing a unique opportunity to bring countries together to harmonize EMF standards, which can provide the same level of health protection to all people. However, given the large existing differences among the different standards around the world, harmonization will not be easy to accomplish. Further reliable and repeatable research on the health effects and suitable exposure thresholds may be needed to reach an agreement among researchers in different countries and to uniformly address public concerns about the safety of RF radiation within exposure guidelines.

\section{FCC and ICNIRP Guidelines}

Two of the most popular sets of standards are reviewed in this section: the FCC standards [16] that are used in the United States and the ICNIRP standards [17] that are used in most European countries. These two standards, while about 20 years old, are widely used and have involved a great deal of animal research throughout their development.

The FCC and ICNIRP standards are designed principally to protect against thermal hazards since ionizing radiation is not a concern at mmWave frequencies, as shown in the "Fundamentals of mmWave Radiation" section. An SAR value of $4 \mathrm{~W} / \mathrm{kg}$, averaged temporally and spatially over the whole body, was recognized as the key working threshold for harmful biological effects in humans. Two critical experiments, called the behaviordisruption experiments, by de Lorge et al. [25], [26] in the 1980s contributed to this fundamental whole-body SAR threshold that is found in the present RF radiation standards. In these two experiments, de Lorge et al. trained rats and monkeys on an auditory observingresponse task and exposed these animals to RF radiation during their performance. The conclusion from these experiments was that "disruption of behavior occurred when an animal was exposed at an SAR of approximately $4 \mathrm{~W} / \mathrm{kg}$, and disruption occurred after 30$60 \mathrm{~min}$ of exposure and when body temperature increased by $1{ }^{\circ} \mathrm{C}$ " [26]. By a careful and extensive review of the biological, engineering, and scientific literature, the $4 \mathrm{~W} / \mathrm{kg}$ wholebody SAR level is recognized as a working threshold for when RF energy begins to induce undesired biological effects on humans [10]. Certain safety margins have been applied to the fundamental $4 \mathrm{~W} / \mathrm{kg}$ SAR when establishing today's RF radiation guidelines for humans. The FCC's radiation restrictions between $100 \mathrm{kHz}$ and $6 \mathrm{GHz}$ use a safety factor of ten to 
obtain a whole-body average (the incident power is averaged over the whole body) SAR level of $0.4 \mathrm{~W} / \mathrm{kg}$ for occupational exposure. An additional safety factor of five is introduced further for exposure to the general public, giving an average whole-body SAR limit of 0.08 $\mathrm{W} / \mathrm{kg}$.

As mentioned in (2), for a given exposure, the SAR distribution differs from point to point in the human body. It is generally accepted that the maximal localized SAR could be as high as 20 times the whole-body-averaged SAR [38]. Thus, an SAR level of $1.6 \mathrm{~W} / \mathrm{kg}(20 \times 0.08)$ in $1 \mathrm{~g}$ of tissue (1-g SAR) in the head and trunk, and $4 \mathrm{~W} / \mathrm{kg}$ in $10 \mathrm{~g}$ of tissue in limbs $(10 \mathrm{-g}$ SAR) are adopted as the localized SAR limitations for the general public.

The ICNIRP guidelines are similar to those of the FCC, with a few exceptions. The maximum localized SAR limitation of the ICNIRP guidelines is chosen to be $2 \mathrm{~W} / \mathrm{kg}$ in any $10 \mathrm{~g}$ of tissue in the head and trunk and $4 \mathrm{~W} / \mathrm{kg}$ in any $10 \mathrm{~g}$ of tissue in the limbs over 6 min of exposure for frequencies up to $10 \mathrm{GHz}$ for the general public. Aside from the numerical difference between the acceptable SAR in the United States and Europe (1.6 or $2 \mathrm{~W} / \mathrm{kg}$, as shown in Table 2), the tissue mass used to define the SAR in these two standards (the $1 \mathrm{~g}$ for $1.6 \mathrm{~W} / \mathrm{kg}$ approach by the FCC versus $10 \mathrm{~g}$ for $2 \mathrm{~W} / \mathrm{kg}$ by the ICNIRP), both for the head and trunk for the general public, is also different.

It should be evident that 1 -g SAR provides a finer resolution and thus offers a more conservative restriction on the actual energy allowed to be distributed in the tissue. Since a cell phone emits radiation next to a user's body, such as the head, the radiation is nonuniform and varies from one location to another, and this radiation variability will be further exacerbated with directional steerable antennas and phased arrays such as those described in [39] and [40]. An average mass as large as $10 \mathrm{~g}$ would tend to smooth out the SAR distributions and would probably lower the numerical SAR value by a factor of two or more compared with a 1-g SAR. Moreover, the spherically shaped human eye has a total mass of about $10 \mathrm{~g}$, and thus, the use of a 10-g average mass will completely ignore the variation of SAR distribution throughout the eyeball. The 1-g SAR is a more meaningful measure of localized RF radiation absorption and a more biologically significant measure of SAR distribution inside the head or trunk at high frequencies [38]. However, at mmWave frequencies, where most of the energy is absorbed in the few outer millimeters of tissue, even a 1-g averaging volume can seem large.

At mmWave frequencies, as discussed in the "Fundamentals of mmWave Radiation" section (and analyzed in the "mmWave Effects on Skin" section), energy absorption becomes increasingly confined to the surface layers of the skin, and the heating effect is directly related to the incident PD. The PD, and not the SAR, is therefore used currently as a basic restriction in the mmWave exposure guidelines. In other words, the exposure restrictions change from SAR levels to PD levels when moving to higher frequencies (above 6 or 10 $\mathrm{GHz}$, depending on whether the FCC or ICNIRP guidelines are used). Thus, the restrictions move from evaluating the volumetric energy distribution (SAR, below 6 or $10 \mathrm{GHz}$ ) to planar energy distribution (PD, above 6 or $10 \mathrm{GHz}$ ). The FCC guidelines adopt the maximum permissible exposure limits from $0.3 \mathrm{MHz}$ to $100 \mathrm{GHz}$, for electric- and magnetic-field strength and PD restrictions, derived from those recommended by American 
National Standards Institute/IEEE C95.1-1992 [9] and the National Council on Radiation Protection (1986) [41]. The ICNIRP guidelines provide reference levels for electric- and magnetic-field strength and PD from $10 \mathrm{MHz}$ to $300 \mathrm{GHz}$.

Figure 1 compares the FCC and ICNIRP PD restrictions due to electromagnetic wave exposure from $10 \mathrm{MHz}$ to $100 \mathrm{GHz}$. From frequencies between 10 and $30 \mathrm{MHz}$, the FCC guidelines are much more restrictive than the ICNIRP guidelines. Moreover, the ramp-up from 10 to $50 \mathrm{~W} / \mathrm{m}^{2}$ takes place at $300 \mathrm{MHz}$ for the ICNIRP guidelines and $400 \mathrm{MHz}$ for the FCC guidelines. For frequencies from 30 to $300 \mathrm{MHz}$ and frequencies greater than 2 $\mathrm{GHz}$, the two standards are identical. The most stringent requirements are from 30 to 300 $\mathrm{MHz}$ because the human body absorbs energy very efficiently in that range. Interestingly, the FCC and ICNIRP PD restrictions harmonize at the mmWave bands. For far-field exposures where the electric field is uniformly distributed over the human body, the PD should not exceed $10 \mathrm{~W} / \mathrm{m}^{2}\left(1 \mathrm{~mW} / \mathrm{cm}^{2}\right)$ for the general public and $50 \mathrm{~W} / \mathrm{m}^{2}\left(5 \mathrm{~mW} / \mathrm{cm}^{2}\right)$ for the occupational groups. It should be noted that the spatial maximum power densities averaged over $1 \mathrm{~cm}^{2}$ should not exceed $20 \mathrm{~mW} / \mathrm{cm}^{2}$ for the general public and $100 \mathrm{~mW} / \mathrm{cm}^{2}$ for occupation workers. Such exposure conditions may correspond to some near-field scenarios [42], [43], where antennas may be placed directly on the body or integrated into garments. However, the FCC and ICNIRP regulations do not provide a dosimetric quantity for near-field mmWave exposure, perhaps because mmWave products, such as wireless high definition (wirelessHD), wireless gigabit (WiGig), WLAN, or mmWave cell phones did not exist at the time [1]-[3]. In the "Modern mmWave Example Suggesting Temperature-Based Compliance" section, we provide an example of a temperature-based evaluation for safety of exposure to mmWave radiation in the far field from a modern mmWave transmitting device.

Biological studies under mmWave frequencies are sparse relative to the research conducted at UHF/microwave frequencies. Additional studies on the potential biological effects of mmWave radiation may be needed to ensure that the guidelines are modified to be appropriate and scientifically valid for emerging mmWave broadband wireless communication systems, in particular, where adaptive, directional high-gain antennas are used in consumer devices located in close proximity to human tissues.

\section{Challenge of Ensuring Compliance of Modern mmWave Devices with Existing Exposure Guidelines}

In light of the FCC and ICNIRP exposure guidelines given in the "FCC and ICNIRP Guidelines" section, we now consider how the compliance of new mmWave devices should be determined and whether the current exposure guidelines are appropriate. We believe that they are not, as we will now discuss. The FCC regulations provide a supplemental document to describe the compliance evaluation process [44]. The criteria used for different exposure scenarios are listed in Table 3. At frequencies below $6 \mathrm{GHz}$ for a radiation source operating close to the human body (a distance of less than $20 \mathrm{~cm}$ ), such as a cell phone, the FCC instructs that an SAR evaluation should be performed to evaluate compliance. At frequencies below $6 \mathrm{GHz}$ for a radiation source far from the human body, such as a base station, PD evaluation should be performed to evaluate compliance. As discussed in [44], since SAR limits do not apply for devices above $6 \mathrm{GHz}$, PD should be used for the 
evaluation of any device above $6 \mathrm{GHz}$ according to the FCC guidelines. It should be noted that at shorter wavelengths above $6 \mathrm{GHz}$, instead of the usually recommended $20-\mathrm{cm}$ measurement distance for lower frequencies listed in Table 3, reliable PD measurements can normally be made $5 \mathrm{~cm}$ or more from the transmitter. However, if a device normally operates at distances closer than $5 \mathrm{~cm}$ from the human body, [44] advises that PD must be computed using numerical modeling techniques, such as the finite-difference time domain (FDTD) or finite element method (FEM), to determine compliance. Thus, for an mmWave wireless device operating in direct contact or very close to the human body (less than $5 \mathrm{~cm}$ ), the evaluation of compliance with PD limits will be complicated by the definition of PD in the near field of complex antennas of arbitrary geometry and orientation within a close vicinity of the highly reflective tissue boundary, and the results may vary depending on the methods chosen between different parties conducting compliance evaluations.

\section{Modern mmWave Example Suggesting Temperature-Based Compliance}

For an example of future mmWave devices that could soon be used in handheld products, consider a 60-GHz complementary metal-oxide-semiconductor (CMOS) phased-array transceiver for multi-Gb/s wireless communication implemented on a single chip [39], [40] using a 32-element phased array transmitting antenna located on a circuit board next to the chip. It is reasonable to assume that the largest dimension of such a 60-GHz WLAN antenna array is $D \approx 10 \mathrm{~mm}$. Thus, in this example, the far-field distance (Fraunhofer distance $\left.d_{\text {far_field }}=2 D^{2} / \lambda\right)$ is $4 \mathrm{~cm}$. If the output power of this transceiver is $100 \mathrm{~mW}$ and has an antenna gain of $10 \mathrm{~dB}$, then for a person located $1 \mathrm{~m}$ away from the source, the peak PD level at the skin surface given by (5) would be $0.008 \mathrm{~mW} / \mathrm{cm}^{2}$. If the distance decreases to $10 \mathrm{~cm}$, which is still in the far field, the radiation level would be $0.8 \mathrm{~mW} / \mathrm{cm}^{2}$.

Using the body permittivity model and (8) described in the "Millimeter-Wave Effects on Skin" section, the peak local (unaveraged) SAR level for this example would be 0.22 and 22 $\mathrm{W} / \mathrm{kg}$ at the human skin for distances of $1 \mathrm{~m}$ and $10 \mathrm{~cm}$ from the transmitter, respectively. It is important to note that because the penetration depth (skin depth) is very shallow at 60 $\mathrm{GHz}$, these peak SAR values $(0.22$ and $22 \mathrm{~W} / \mathrm{kg})$ are much greater than the SAR values that would occur at microwave frequencies (e.g., 0.004 and $0.4 \mathrm{~W} / \mathrm{kg}$ if the same transmitter operated at $2 \mathrm{GHz}$ ). However, the relative steady-state temperature increment for an FCCallowable incident PD of $1 \mathrm{~mW} / \mathrm{cm}^{2}$ (which is higher than the PD level of $0.008 \mathrm{~mW} / \mathrm{cm}^{2}$ at $1 \mathrm{~m}$ and $0.8 \mathrm{~mW} / \mathrm{cm}^{2}$ at $10 \mathrm{~cm}$ for this example) shown in Table 1 at $60 \mathrm{GHz}$ is only $0.1{ }^{\circ} \mathrm{C}$ [42], much lower than the temperature variation of the environment. Thus, it is reasonable to expect that no adverse thermal effects need to be considered in this example. Also, we can see from this example that, although the peak SAR on the human surface appears to be very high for this $60-\mathrm{GHz}$ example, the temperature elevation is quite low and well within thermal safety levels, thus confirming that the SAR limits are not appropriate to be used at mmWave frequencies. Although thermal effects are negligible at such a low intensity, further studies are needed to investigate the possible nonthermal bioeffects induced by lowintensity mmWave radiations.

In the example, the distances between the individual and mmWave device are $1 \mathrm{~m}$ or $10 \mathrm{~cm}$, well within the far field for many mmWave portable devices [40]. However, if the 
separation distance is less than $4 \mathrm{~cm}$ under normal use, the tissue will be exposed to nearfield radiation and (4) can no longer be used. In this situation, numerical simulation methods, such as FDTD or FEM, can be used to evaluate exposure to electromagnetic energy and the resulting temperature increase [18]. These methods are used routinely in safety evaluations for communication devices at lower frequencies but are not yet widely established at mmWave frequencies, where wavelengths and skin depths are much smaller than the dimensions of the human subject and where adaptive phased array antennas will be used [40]. Therefore, we suggest that performing temperature elevation measurements for the compliance evaluation of mmWave wireless devices operating very close to the human body may be more meaningful and useful to assure the safety of devices introduced into the marketplace as well as to validate numerical simulations at these frequencies. Simulations and measurements of temperature and temperature increase in the near field of mmWave devices should be more valuable than estimates of PD alone since temperature elevation has a more straightforward relationship with thermal safety than PD.

\section{mmWave Effects on Eyes}

Among human tissues, the eyes are particularly vulnerable to mmWave radiation-induced heating as they are located on the surface of the body. Unlike other parts of the body, such as the hands and arms, which allow heat to be easily dissipated due to blood flow, the eyes lack sufficient blood flow to redistribute the generated heat. Thus, care should be taken to prevent unsafe overexposure of the eyes.

Several previous studies have investigated ocular injuries caused by mmWave exposure (see Table 4). Studies performed in nonhuman primates showed that $60-\mathrm{GHz} \mathrm{mmWave}$ radiation at $10 \mathrm{~mW} / \mathrm{cm}^{2}$ for $8 \mathrm{~h}$ demonstrated no ocular damage [45], thus validating the view that mmWave radiation under the PD restrictions listed in Table 1 causes no ocular damage. Chalfin et al. [46] indicated that corneal damage in the primates' eyes caused by $35-\mathrm{GHz}$ mmWave exposures at $2 \mathrm{~W} / \mathrm{cm}^{2}$ for $1.5-5 \mathrm{~s}$ healed within $24 \mathrm{~h}$. Rosenthal et al. [47] reported that $35-$ or $107-\mathrm{GHz} \mathrm{mmWave}$ exposures at $50 \mathrm{~mW} / \mathrm{cm}^{2}$ for $15-80 \mathrm{~min}$ induced both epithelial damage and stromal edema in the cornea of rabbit eyes, although they began to recover the next day. Kojima et al. [48] showed that corneal edema and corneal desiccation were found after high-intensity exposure of rabbit eyes at $60 \mathrm{GHz}(1,898$ $\left.\mathrm{mW} / \mathrm{cm}^{2}, 6 \mathrm{~min}\right)$. It can be seen that the adverse effects of mmWave exposure on eyes are dependent on the intensity and duration of the exposure. Numerical models of heat transfer in rabbit eyes, nonhuman primate eyes, and human eyes have been published that allow for the evaluation of the temperature distribution of eyes resulting from mmWave exposure [49]-[52]. While levels and durations of far-field radiation in the mmWave band that are hazardous to the eyes have been fairly well characterized, depending on the determination of near-field exposures and the resulting temperature increase from specific mmWave devices, further experiments to definitively demonstrate safety on a case-by-case basis may be prudent. 


\section{mmWave Effects on Skin \\ Dielectric Properties of the Skin}

Human skin consists of two primary layers: an outer epidermis and an underlying dermis. The thickness of the human epidermis and dermis varies in the range of 0.06-0.1 and 1.2$2.8 \mathrm{~mm}$, respectively. The surface layer of the epidermis is called the "stratum corneum" with a thickness of $0.012-0.018 \mathrm{~mm}$. The stratum corneum has low water content (15-40\%), and the total water concentration in the rest of the epidermis and dermis is $70-80 \%$. Since mmWave energy is attenuated very rapidly in moist aqueous tissue, this high water content leads to high absorption coefficients of mmWave electromagnetic energy in the tissue. Thus, mmWave energy penetrates the stratum corneum easily but is rapidly absorbed within the deeper epidermis and dermis and does not propagate further into the body [42], [53].

The dielectric properties of skin are characterized from measurements of its relative complex permittivity

$$
\varepsilon^{*}=\varepsilon^{\prime}-j \varepsilon^{\prime \prime}
$$

where

$$
\varepsilon^{\prime \prime}=\frac{\sigma}{2 \pi f \varepsilon_{0}},
$$

where $\sigma$ is the conductivity of the material measured in Siemens/meter and $\varepsilon_{0}$ is the permittivity of free space given by $8.85 \times 10^{-12} \mathrm{~F} / \mathrm{m}$.

Existing measured data of skin permittivity is rare in the mmWave band compared with frequencies below $20 \mathrm{GHz}$ due to technical limitations, such as availability of vector network analyzers, in the mmWave frequency range. Gabriel et al. [54]-[56] and Gandhi and Riazi [57] presented complex permittivity of human skin for the mmWave band based on extrapolation of experimental data at microwave frequencies, and they developed models in terms of four-term Cole-Cole dispersion and single Debye dispersion, respectively.

Alabaster [58] measured the complex permittivity of an ex vivo sample of human skin over the mmWave band from 60 to $100 \mathrm{GHz}$ using a quasi-optical method. The measured results were compared with predictions from Gabriel's model. The results showed a consistently higher real part of the permittivity than the predicted values, although the imaginary values were in reasonable agreement. Alekseev and Ziskin (in vivo) [53], Hwang et al. (in vivo, epidermis only) [59], and Chahat et al. (in vivo) [60] also conducted direct measurements at mmWave frequencies characterizing the complex permittivity of human skin and proposed broadband Debye and Cole-Cole models based on their measurement results. The Debye and Cole-Cole models are summarized in Table 5, where $\tau$ is the relaxation time (in dipolar relaxation mechanisms, related to the time required for a single molecular dipole in the tissue to reach equilibrium with the application or removal of an applied field), $\omega$ is the angular frequency, $\varepsilon_{\infty}$ is the permittivity at frequencies where $\omega \tau>>1, \varepsilon_{s}$ is the permittivity at frequencies where $\omega \tau<<1, a$ denotes the spread in relaxation time, $\varepsilon_{0}=8.85$ 
$\times 10^{-12} \mathrm{~F} / \mathrm{m}$ is the permittivity of free space, $\sigma_{S}(\mathrm{~S} / \mathrm{m})$ is the static skin ionic conductivity (ionic conductivity relates to how well a material conducts electricity), and $\Delta \varepsilon_{s}=\varepsilon_{s}-\varepsilon_{\infty}$. The skin permittivity parameters in Debye and Cole-Cole models measured by the previously mentioned researchers are summarized in Tables 6 and 7 .

Figures 2 and 3 show the relative permittivity and conductivity of the skin derived from the skin model parameters listed in Tables 6 and 7. From 10 to $100 \mathrm{GHz}$, the relative permittivity of skin decreases with the increase of frequency, whereas the conductivity of the skin increases with the increase of frequency. From the studies by Alekseev and Ziskin [53] and Chahat et al. [60] on the palms and wrists/forearms, we see that the conductivity of the human palm is lower (and thus will absorb less power), which stems from the fact that the outer skin layer with the lowest water content is thicker at the palm than at the wrist and forearm. Moreover, the predicted results of Alekseev's forearm model agree well with those of Gabriel's skin model. However, when comparing the relative permittivity of Alekseev's and Chahat's forearm (or palm) models, the discrepancy is greater than $20 \%$, as shown in Figure 2. The discrepancies between these studies, as shown in Figures 2 and 3, may be related to the intrinsic differences of measurement methods and may possibly be due to the variations of sample types, such as the skin temperature and thickness of different skin layers. It must be noted that many scientific papers make use of the dielectric properties provided by Gabriel et al. at frequencies below $100 \mathrm{GHz}$, and these data have become widely available through some online databases [61], [62]. However, these data have natural variability in the structure and composition of the biological tissues [55]. Due to the importance of accurate dielectric permittivity for the research of mmWave interactions with the human body, further measurements of different body sites and different human subjects are warranted to characterize the variability and distribution of properties for the development of accurate models.

\section{Reflection and Transmission in the Skin}

Since wavelengths in the mmWave band are very small $(1-10 \mathrm{~mm})$ compared with the dimensions of the human body, it is reasonable to model the human skin as a semi-infinite flat surface considering a plane-wave at the mmWave band illuminating the skin surface. Thus, the reflection coefficients for the components of an arbitrary wavefront having parallel polarization (the $E$-field is parallel to the surface of the skin at any angle of incidence) and perpendicular polarization (the $E$-field is increasingly perpendicular to the surface of the skin with the increasing angle of incidence) at the boundary of air and skin are given by [19]

$$
\begin{aligned}
& R_{p}=\left|\frac{-\varepsilon^{*} \cos \theta_{i}+\sqrt{\varepsilon^{*}-\sin ^{2} \theta_{i}}}{\varepsilon^{*} \cos \theta_{i}+\sqrt{\varepsilon^{*}-\sin ^{2} \theta_{i}}}\right| \\
& R_{\perp}=\left|\frac{\cos \theta_{i}-\sqrt{\varepsilon^{*}-\sin ^{2} \theta_{i}}}{\cos \theta_{i}+\sqrt{\varepsilon^{*}-\sin ^{2} \theta_{i}}}\right|,
\end{aligned}
$$


where $\theta_{i}$ is the angle between the direction of the mmWave incident on the skin surface and a line perpendicular to the skin surface. The power reflection coefficient and power transmission coefficient are $R_{p}^{2}$ (or $R_{\perp}^{2}$ ) and $1-R_{p}^{2}$ (or $1-R_{\perp}^{2}$ ), respectively.

Figure 4 shows the power reflection coefficients at the air and skin interface at $60 \mathrm{GHz}$ for parallel and perpendicular polarized components using the various skin model parameters listed in Tables 6 and 7. The results show that at $60 \mathrm{GHz}, 30-40 \%$ of the incident power is reflected at the skin surface. At a small angle of incidence, the power reflection coefficients may change by $20 \%$ or more for various, currently available, relative complex permittivity values.

Figure 5 shows the relationship of power reflection coefficients and various frequencies using Gabriel's skin model for parallel and perpendicular polarization. It can be seen that at $40 \mathrm{GHz}$, about $43 \%$ of the incident power, is reflected at the skin surface for a normal incident plane-wave, whereas at $100 \mathrm{GHz}$, the power reflection coefficient decreases to $30 \%$. This implies that more power is transmitted into the human body at higher frequencies. The Brewster angles, where almost all energy for parallel polarization is absorbed in the human skin, lie in the range of $60^{\circ}$ to $80^{\circ}$ at various frequencies.

The SAR value at the surface of the skin is [57], [63]

$$
S A R(0)=\frac{2 P_{i n c}\left(1-R^{2}\right)}{\rho \delta},
$$

where $P_{\text {inc }}$ is the incident PD, $\rho$ is the mass density $\left(1.0 \mathrm{~g} / \mathrm{cm}^{3}\right.$ is used in the calculation), and $\delta$ is the penetration depth (or skin depth, corresponding to the PD of $1 / e^{2}$ or $13.5 \%$ of that transmitted across the surface) of the plane-wave.

The SAR at a depth $x$ within the skin is given by

$$
S A R(x)=S A R(0) e^{-\frac{2 x}{\delta}} .
$$

Figure 6 shows the penetration depth in the human body using different skin model parameters at various frequencies. The penetration depth decreases rapidly with the increase of frequency. Figure 7 shows the attenuation of the SAR in the skin layer for an FCC and ICNIRP allowable incident PD of $10 \mathrm{~W} / \mathrm{m}^{2}$ at $60 \mathrm{GHz}$. The remaining transmitted power in the skin decreases exponentially in the skin as a function of depth. From Figures 6 and 7, we can see that more than $90 \%$ of the transmitted electromagnetic power is absorbed within the epidermis and dermis layers and little power penetrates further into deeper tissues (although as shown next, the heating of human tissue may extend deeper than the epidermis and dermis layers). Therefore, a single-layer or a multilayer skin model is sufficient to reliably evaluate mmWave reflection and electromagnetic penetration in the skin. 


\section{mmWave Heating of the Skin}

Since most mmWave energy is absorbed near the surface of the human body, leading to localized temperature elevations near the skin surface, the study of mmWave heating of the skin is critical to protecting humans from mmWave overexposure.

The temperature elevation of human skin exposed to electromagnetic waves was studied in a number of previous works. At microwave frequencies, the fundamental characteristics of absorption of electromagnetic waves and the effects of radiation on temperature elevation were investigated by many researchers [24], [64]-[67]. In the mmWave frequency regime, several pioneering studies have contributed to the thermal modeling and experimental approaches. Walters et al. [68] conducted thermal measurement in ten human subjects during $94-\mathrm{GHz}$ continuous mmWave radiation at intensities up to $18,000 \mathrm{~W} / \mathrm{m}^{2}$. They found that the threshold PD for pain sensation was $12,500 \pm 500 \mathrm{~W} / \mathrm{m}^{2}$ for a 3 -s exposure, which corresponded to a mean increase in surface temperature of $9.9^{\circ} \mathrm{C}$ from an average baseline (pre-exposure) temperature of $34.0 \pm 0.2^{\circ} \mathrm{C}$ to an average final threshold temperature of $43.9 \pm 0.5^{\circ} \mathrm{C}$ at the end of the 3-s exposure. Alekseev and Ziskin [69] demonstrated that it was more accurate to describe the temperature distributions during mmWave heating with a multilayer model of skin since heating due to local mmWave exposure affected not only skin but also the subcutaneous tissues, including the fat and muscle. Alekseev et al. [70] also indicated that blood flow served to reduce the temperature elevation induced by mmave radiation.

Nelson et al. [71] reported the thermal modeling results of a heterogeneous primate head model for mmWave heating. This work revealed that the surface temperature increased with energy density and was affected by various environmental conditions, such as perfusion, convection, and sweat rate. Also, they concluded that the metabolic rate did not significantly affect the magnitude of the temperature increase. Kanezaki et al. [72] investigated the analytical solution of the bioheat equation in [73] [see (10) discussed subsequently] for a one-dimensional (1-D) three-layer human model using the Laplace transform. Kanezaki et al. [74] also performed a parametric analysis of the steady-state temperature elevation of a one- and three-layer human model, where the paper reported that the surface temperature elevation in the three-layer model was 1.3-2.8 times greater than that in the one-layer model due to the thermally insulating nature of the fat layer. They also showed that the dominant parameter influencing the surface temperature elevation was the heat transfer coefficient between the body surface and air. Chahat et al. [75] presented a broadband tissue-equivalent phantom in the 55-65-GHz range for emulating the dielectric properties of human skin for reproducible, well-controlled characterization of wearable antennas, on-body propagation channels, and absorption of the electromagnetic power by the human body. The use of such a phantom is also important for the experimental safety assessments of mmWave systems and devices. Zilberti et al. [76], [77] reported on how the uncertainty and variability of the electric and thermal properties of tissues could affect the estimation of temperature elevation produced during mmWave exposures using a 1-D three-layer human skin model. Combining all of the relevant parameters, they showed that the deviation from the reference solution of the maximum temperature elevation in the skin was included in the coverage intervals from $-30 \%$ to $+10 \%$ at $100 \mathrm{GHz}$ with a $95 \%$ confidence level. Zilberti's results reinforce the 
importance of sound databases of tissue properties when making safety assessments of mmWave applications.

Most of the theoretical analyses on heat transfer in living tissue are based on the bioheat transfer equation in [73]. The bioheat transfer equation, given in (10), describes the influence of blood flow on the temperature distribution in the tissue in terms of volumetrically distributed heat sinks or sources

$$
\rho c \frac{\partial T}{\partial t}=\nabla \cdot(k \nabla T)+\left[-\rho_{\text {blood }} w \cdot c_{\text {blood }}\left(T-T_{\text {blood }}\right)\right]+Q_{m}+S A R \cdot \rho,
$$

where $\rho$ is the mass density $\left(\mathrm{kg} / \mathrm{m}^{3}\right)$ in the corresponding tissue layer, $\rho_{\text {blood }}$ is the mass density $\left(\mathrm{kg} / \mathrm{m}^{3}\right)$ of blood, $c$ is the specific heat capacity $\left(\mathrm{J} / \mathrm{kg} /{ }^{\circ} \mathrm{C}\right)$ in the corresponding tissue layer, $c_{\text {blood }}$ is the specific heat capacity $\left(\mathrm{J} / \mathrm{kg} /{ }^{\circ} \mathrm{C}\right)$ of blood, $k$ is the thermal conductivity $\left(\mathrm{W} / \mathrm{m} /{ }^{\circ} \mathrm{C}\right), w$ is the perfusion by blood $(\mathrm{mL} / \mathrm{g} / \mathrm{s}), T$ is the tissue temperature $\left({ }^{\circ} \mathrm{C}\right), T_{\text {blood }}$ is the blood temperature $\left({ }^{\circ} \mathrm{C}\right)$, SAR $\cdot \rho\left(\mathrm{W} / \mathrm{m}^{3}\right)$ is the volumetric heat source distributed in the tissue, and $Q_{m}\left(\mathrm{~W} / \mathrm{m}^{3}\right)$ is the heat generated by metabolism.

Now, we use a 1-D three-layer human tissue model (Figure 8) and consider the effects of blood flow to simulate and analyze the steady-state temperature elevation. To simplify the problem, we assume a continuous plane-wave with radiation frequency $f$ normally incident on the surface of human tissue consisting of skin, subcutaneous adipose tissue (SAT), and muscle. The model is indefinite on the $x y$ plane and infinite along the $z$ axis. Due to the 1-D nature of the model, the temperature in each homogeneous biological layer can be described using the 1-D version of the bioheat transfer equation given by [76]

$$
\rho c \frac{\partial T}{\partial t}=k \frac{\partial^{2} T}{\partial z^{2}}-h_{b}\left(T-T_{b l o o d}\right)+Q_{m}+S A R \cdot \rho,
$$

where $h_{b}=\rho_{\text {blood }} w \cdot c_{\text {blood }}$.

Equation (11) is solved using the analytical method and boundary conditions described in [76]. The tissue properties listed in Tables 8 and 9 have been chosen according to the database developed in [62]. In some simulations, the thickness of an additional layer of clothing is $1 \mathrm{~mm}$ (if not specified) with a relative complex permittivity of $1.6+j 0.06$, which is estimated from the complex permittivity of denim measured at $40 \mathrm{GHz}$ [78]. $T_{\text {blood }}$ is 37 ${ }^{\circ} \mathrm{C}$ and $T_{\text {air }}$ is $23{ }^{\circ} \mathrm{C}$ in the simulation. Finally, the boundary condition for steady-state temperature elevation is set to be $0{ }^{\circ} \mathrm{C}$ at a depth of $35 \mathrm{~mm}$ inside the tissue.

The distributions of SAR $\cdot \rho$ in the human tissue due to $10 \mathrm{~W} / \mathrm{m}^{2}$ (FCC and ICNIRP PD restrictions for the general public) at various mmWave frequencies are plotted in Figure 9. At various frequencies, the heating power is dissipated in the shallow surface of skin, thus confirming that the radiation power is confined to a shallower depth at a higher frequency, as stated previously. For frequencies from 40 to $100 \mathrm{GHz}, \mathrm{SAR} \cdot \rho$ is attenuated to negligible levels within the skin, and thus, the power distribution in human tissue is determined by the electromagnetic properties of skin. This implies that a single-layer human tissue model is sufficient for the analysis of power deposition in human tissue. 
Figure 10 shows the steady-state temperature elevation at $60 \mathrm{GHz}$ with incident power densities of 0.1 (the PD restrictions for China, Russia, Switzerland, and Italy as listed in Table 1), 1, 10 (the FCC and ICNIRP PD restrictions for the general public), and $50 \mathrm{~W} / \mathrm{m}^{2}$ (the FCC and ICNIRP PD restrictions for occupational exposure). We can see that the temperature elevation is proportional to the intensity of incident power densities. When the incident $\mathrm{PD}$ is $50 \mathrm{~W} / \mathrm{m}^{2}$, the temperature elevation at the skin surface is about $0.8{ }^{\circ} \mathrm{C}$, which is below the temperature elevation threshold of $1{ }^{\circ} \mathrm{C}$ in the IEEE guideline on mmWave radiation [10].

Figure 11 compares the temperature elevations at incident power densities of 10 and 50 $\mathrm{W} / \mathrm{m}^{2}$ due to $60-\mathrm{GHz}$ exposure in a one-layer human tissue model (skin only) and a threelayer human tissue model. The peak steady-state temperature elevations for 10 and $50 \mathrm{~W} / \mathrm{m}^{2}$ exposure in the one-layer human tissue model are 0.1 and $0.5^{\circ} \mathrm{C}$, respectively, which agrees very well with the one-layer model results presented in [42]. However, for the three-layer human tissue model, the peak temperature elevations are higher, at 0.16 and $0.8{ }^{\circ} \mathrm{C}$, respectively, for 10 and $50 \mathrm{~W} / \mathrm{m}^{2}$ exposure. This implies that the structure of the model plays an important role in evaluating the thermal effects of mmWave radiation in the body [69]. As reported in [74], the surface temperature elevation in the three-layer model is 1.32.8 times greater than that in the one-layer model due to the thermally insulating nature of the fat layer. Thus, accurate human body models are needed to predict the temperature elevation for safety assessments due to mmWave radiation.

The previously described analysis could be considered a best-case scenario, where the mmWave energy is incident on naked skin in a room-temperature environment. For consideration of a very extreme case, where the skin is covered with thick clothing, such as a hat, and where there is relatively little thermal conduction through the skin, the steadystate temperature elevation on the skin surface for a $60-\mathrm{GHz}$ plane-wave with $10 \mathrm{~W} / \mathrm{m}^{2}$ intensity illuminating the clothing surface (with a thickness of $1 \mathrm{~mm}$ ) can reach $0.3{ }^{\circ} \mathrm{C}$. Thus, for the same incident PD, the steady-state temperature elevation in the tissue is highly related to the tissue model used.

\section{Propagation Through Clothing and Garment Materials}

For future body-centric wireless communications or for the detection of concealed threats, such as weapons on or in the human body, it is important to assess the effects of clothing and garment materials on mmWave absorption as these materials may change the effects of mmWave radiation on the skin.

Bjarnason et al. [79] measured the attenuation of eight common garment materials (wool, linen, leather, denim, naugahyde, silk, nylon, and rayon) with thicknesses less than $2.2 \mathrm{~mm}$ over the frequency range $100 \mathrm{GHz}-1.2 \mathrm{THz}$. The attenuation caused by each of the material samples never exceeded $3 \mathrm{~dB}$ for all measured frequencies below $350 \mathrm{GHz}$. Gatesman et al. [80] measured the attenuation of six different garment materials (cotton shirt, denim, drapery, leather, sweater, and sweatshirt) with thicknesses less than $2.1 \mathrm{~mm}$ for parallel and perpendicular incidence polarization. The materials again did not show more than $3 \mathrm{~dB}$ attenuation in transmitted power until above $350 \mathrm{GHz}$. There is little difference in the attenuation between two polarizations. Zhadobov et al. [42] computed the transmission 
coefficient of dry fleece with thickness ranges between 0 and $1.2 \mathrm{~mm}$ at $60 \mathrm{GHz}$ using Gabriel's skin permittivity data $(7.98$ - j10.90) [56]. The results showed that clothing in direct contact with the skin might act as an impedance transformer [57], resulting in the enhancement of the power transmission into the body, whereas an air gap of 0-2 mm between the clothes and skin decreases the body transmission. The results of these studies show that mmWave attenuation of most garment materials is negligible.

\section{Interactions Between mmWave Antennas and the Human Body}

At microwave frequencies, it is widely accepted that antennas placed in close proximity to lossy media, such as the human body, experience strong power absorption into the media, radiation pattern distortion, shift in resonance frequency, and change in the input impedance [81], [82]. In the mmWave band, the electromagnetic coupling between antennas and the human body as well as the possible perturbations of antenna characteristics due to the body require more study.

Chahat et al. [63] investigated the interaction between a 60-GHz microstrip patch antenna array and the human body both numerically and experimentally. Using a skin-equivalent phantom, it was demonstrated that the impedance matching and the antenna gain were virtually unaffected by the presence of the body. Furthermore, an incident PD of 7.3 $\mathrm{mW} / \mathrm{cm}^{2}$ and a peak SAR of $169.2 \mathrm{~W} / \mathrm{kg}$ were found experimentally with an input power of $322 \mathrm{~mW}$ and an antenna/body spacing of $5.6 \mathrm{~mm}$. In [63], the heating effects from the presented SAR and PD values were not discussed, and it is worth noting that these levels exceed the current exposure guidelines presented in Tables 1 and 2. However, based on our analysis in the "Modern mmWave Example Suggesting Temperature-Based Compliance" section, such high values may not lead to substantial temperature elevation at mmWave frequencies and may thus be safe. More studies are needed to verify whether the existence of the human body may affect the antenna performance as well as the appropriate exposure guidelines that may include temperature variation metrics.

\section{Reported Effects at Cellular and Molecular Levels}

Compared with lower frequency bands, relatively little careful research has been conducted evaluating the potential of more subtle long-term effects than tissue damage due directly to heating at mmWave frequencies. In the tens to hundreds of megahertz, the use of electromagnetic energy to selectively heat tumors by only a few degrees for extended periods of time has shown promise as a treatment for cancer either alone or in combination with other therapies [83]. These effects are decidedly thermal in nature. There are also a variety of studies reporting effects that cannot necessarily be associated with a definite increase in temperature. In the low-gigahertz range, where cell phones and wireless networks now operate, a wide variety of studies, ranging from prospective studies in cell cultures to retrospective epidemiological studies, have failed to show conclusive, consistent evidence for deleterious effects of low-level exposure. Although the IEEE International Committee on Electromagnetic Safety has issued statements indicating that this can be interpreted to mean that these nonthermal effects likely do not exist [9], [10], the FCC and the World Health Organization have made more precautionary statements, publicly 
discussing both the lack of conclusive evidence for long-term adverse effects of cell phone use and the need for more studies before any contrary conclusion is reached [84], [85].

The reported bioeffects of mmWave radiation have included effects on cell growth and proliferation rates, activity of enzymes, state of the cell genetic apparatus, function of excitable membranes and peripheral receptors, rates of stress reactions, rates of tissue repair and regeneration, and other bioeffects [88]. While many times, these effects appear to not have any clear association with temperature increase, in other cases, the association (or lack thereof) is not as clear. For example, Chatterjee et al. [89] reported the possibility of nonthermal bioeffects at $94 \mathrm{GHz}$ on skeletal muscle. They reported that repeated RF exposures caused a reproducible decrease in force production. While they noted no increase in temperature, they could not rule out temperature increase in the muscle because they only measured the temperature of the fluid forcibly circulated around the excised muscle. At the same time, they could only measure an effect for applied mmWave electric field magnitudes in excess of 2,600 V/m. In muscle tissue, this would result in SAR $\cdot \rho$ levels well in excess of $1,000,000 \mathrm{~W} / \mathrm{m}^{3}$, which would certainly be expected to cause a notable increase in temperature and is far beyond the levels expected for mmWave communication devices.

Research has been conducted on the biological effects of mmWaves from many different perspectives. Pakhomov et al. [6] reviewed the state and implications of biological effects of mmWaves, mainly focusing on the mmWave radiation effects on the body's cellular and molecular levels. Many of the reported effects discussed in [6] indicated nonthermal mechanisms that were used in therapeutic applications. They suggested that the possibility of significant bioeffects of a short-term mmWave irradiation at intensities at or below current safety standards deserves consideration and further study. A number of researchers, many in Eastern Europe, have expressed interest in the therapeutic application of mmWave radiation. MmWave therapy has been widely used in Eastern Europe since the 1970s [86].

Strikingly high success rates have been reported in the treatment of gastric ulcers, cardiovascular diseases, respiratory sickness, tuberculosis, skin diseases, and even cancer [6], [87]. Typical treatments consist of daily skin exposure of 15-30 min for 5-15 days with PD levels under $10 \mathrm{~mW} / \mathrm{cm}^{2}$ at three common frequencies: 42.2, 53.6, and $61.2 \mathrm{GHz}$ [90]. The mechanisms of mmWave therapy are not known. Nevertheless, some hypotheses have been explored in cellular and molecular levels in recent years as discussed in the "Reported Effects on Gene Expression," "Reported Effects on Cellular Proliferation," and "Reported Effects on Biological Membranes" sections. Despite the large number of patients treated with mmWaves in Eastern Europe, this therapeutic technique has not been accepted by Western physicians and scientists.

It is also important to note that many of the reports summarized in this section have not been independently repeated and confirmed. Historically, some attempts to repeat reported effects have been unsuccessful [8], [91]. While this is not to discount any one of the studies summarized here, it is important to recognize that studies involving biological samples inherently produce variable results and (depending on the circumstances) may have a number of uncontrolled or uncontrollable variables. For this reason, major decisions on public policy or health care should not typically be made based on reports that were not reproduced independently. 


\section{Reported Effects on Gene Expression}

Gene expression is the process where information from a gene in a living organism is used to synthesize a gene product such as a protein. The study of gene expression enables us to understand how cells sense and react to mmWave radiation. Logani et al. [92] published results of the genotoxic potential of $42.2 \pm 0.2-\mathrm{GHz}$ mmWave radiation on adult male mice. This investigation aimed to determine the genotoxic potential (e.g., a potential cause of cancer) of mmWaves that might induce genetic damage since such damage is often related to carcinogenesis. The incident PD used in [92] was $31.5 \pm 5.0 \mathrm{~mW} / \mathrm{cm}^{2}$ with a peak SAR of $622 \pm 100 \mathrm{~W} / \mathrm{kg}$ (several times greater than those reported in [63] for a 60-GHz transmitter with a directional patch antenna). Logani et al. [92] concluded that mmWaves are not genotoxic, which is perhaps not surprising due to the nonionizing nature of the mmWave band. Quément et al. [93] reported a thorough study showing that mmWave exposure at 60.4 $\mathrm{GHz}$ with an average incident power of $1.8 \mathrm{~mW} / \mathrm{cm}^{2}$ and an average SAR of $42.4 \mathrm{~W} / \mathrm{kg}$ did not have any dramatic impact on primary human keratinocyte cells. Zhadobov et al. [94] presented a study on the influence of low-PD $\left(5.4-\mu \mathrm{W} / \mathrm{cm}^{2}\right.$ or $\left.0.54-\mathrm{mW} / \mathrm{cm}^{2}\right) \mathrm{mmWave}$ radiation at $60 \mathrm{GHz}$ of stress-sensitive gene expression of molecular chaperones in a human brain cell line. The main results showed that low-PD 60-GHz radiation did not modify the stress-sensitive gene expression of chaperone proteins. These studies support the view that nonionizing mmWave radiation should not induce cancer.

\section{Reported Effects on Cellular Proliferation}

One of the major side effects of conventional drug therapy, such as cyclophosphamide (CPA) in cancer treatment, without mmWave radiation, is that it can enhance tumor metastasis due to suppression of natural kill (NK) cell activity. Beneduci et al. [95] studied the antiproliferative effects of low-power (less than $50 \mu \mathrm{W}$ ) mmWave radiation on the human tumor cells and presented that RF radiation in the 50-80-GHz range helped stop the proliferation of tumor cells. Radzievsky et al. [96] at Temple University found that a 61.22$\mathrm{GHz} \mathrm{mmWave}$ signal $\left(13.3 \mathrm{~mW} / \mathrm{cm}^{2}\right)$ was able to suppress subcutaneous tumor growth. Logani et al. [97] studied the effects of mmWave radiation $\left(36.5 \pm 5 \mathrm{~mW} / \mathrm{cm}^{2}\right)$ on tumor metastasis and found that mmWaves could increase NK cell activity suppressed by CPA, suggesting that a reduction in tumor metastasis by mmWaves is mediated through the activation of NK cells. Thus, they hypothesize that the apparent beneficial effects of mmWaves in cancer treatments were due to indirect effects. It was proposed that mmWaves could stimulate the immune system, which could in turn remove the tumor via mechanisms already well known and used in immunotherapy [98].

\section{Reported Effects on Biological Membranes}

Biological membranes are structures that act as a selectively permeable barrier within living things. They separate cells from their surrounding mediums and often consist of a phospholipid bilayer with embedded proteins used in the communication and transportation of chemicals and ions. Several studies have reported that this membrane may be affected by mmWaves. Zhadobov et al. [99] suggested that $60-\mathrm{GHz}$ mmWave exposure at PD levels close to typical wireless communication systems $\left(0.9 \mathrm{~mW} / \mathrm{cm}^{2}\right)$ induced an increase of lateral pressure in the artificial membranes. Szabo et al. [100] also demonstrated that 
modification was observed without cellular damage in cellular membranes during the exposure at $42.2 \mathrm{GHz}$ at a PD level of $35.5 \mathrm{~mW} / \mathrm{cm}^{2}$, suggesting that such a modification could play a role in the cellular signaling or interactions. It was also demonstrated that exposure to 53.3 or $130 \mathrm{GHz}\left(7.3 \mathrm{~mW} / \mathrm{cm}^{2}\right)$ modified the shape and enhanced the permeability of liposomal vesicles, which implies that membranes are affected by mmWave radiation [101], [102]. The mechanisms of mmWave on biological membranes remain unknown, but it is conceivable that the mmWave radiation can interfere with the orientation of charged and dipolar molecules in the membranes. If such a change modified the neural membrane's permeability, it could stimulate neuron endings or affect the electric signal transmitted to the rest of the body, thus modifying environmental perception, including pain sensation [98]. However, reorientation of large dipolar molecules by applied oscillating EMFs, even when they are free to rotate and are not bound by other molecules as in a membrane, is not known to occur above the low-megahertz regime, and would be hard to explain by currently understood mechanisms of interaction [7]. Before these reported effects could influence regulatory guidelines, at a minimum, independent demonstration of reproducibility would be required.

\section{Reported Effects on Immune and Inflammatory Systems}

The effects of mmWaves on the immune system have been thoroughly studied, and several works report that mmWaves can enhance the human immune system [42], [98], [103]. Makar et al. [104] reported that mmWaves can inhibit CPA-induced suppression of T-cells' activation and proliferation. The same research group also found that $42.4 \mathrm{GHz}$ at 31 $\mathrm{mW} / \mathrm{cm}^{2}$ could activate NK cell functions [105], which was also confirmed in [97].

Early experiments with wounded rabbits, mice, and other laboratory animals found that a wounded surface under the exposure of mmWaves healed two times faster than if no radiation was applied [103]. Low-intensity $\left(0.1 \mathrm{~mW} / \mathrm{cm}^{2}\right) 42-\mathrm{GHz}$ mmWave exposures were also reported to have anti-inflammatory actions on humans [106], [107]. It has been observed that mmWaves have the ability to cause healing of wounded skin without scars. Several beauty clinics in the former Soviet Union have used mmWave therapy in cosmetology [103].

\section{Conclusions}

This article presents a literature review of the current understanding of the potential biological effects of nonionizing mmWave radiation on the human body with a focus on what is required to ensure the safety of emerging mmWave technologies for next-generation (5G) mobile communications networks.

Of the quantities currently used for regulating the intensity of nonionizing radiation, PD is currently preferred at mmWave frequencies because of (among other things) the difficulty in defining a meaningful volume for SAR evaluation when penetration depths are very small. However, this quantity does not consider the reflection or transmission of mmWave energy across boundaries or the transfer of heat either between tissues or between tissues and the environment. We propose that in the future, temperature could be considered an acceptable 
quantity for demonstrating safety (as it is in the magnetic resonance imaging industry [108]) because it is much more directly relevant to any actual possibility of damage.

We highlighted the findings of mmWave radiation studies on the eyes and skin since, in communication applications, these tissues would receive the most radiation, with other tissues receiving, by comparison, a negligible amount. Ocular injury can be induced by short-term high-intensity exposure (e.g., 2,000 $\mathrm{mW} / \mathrm{cm}^{2}, 1.5-5 \mathrm{~s}$ ) far beyond the anticipated future communication device levels, but the eyes do not appear to suffer damage from longer low-intensity exposure (e.g., $10 \mathrm{~mW} / \mathrm{cm}^{2}, 8 \mathrm{~h}$ ), which might be experienced from mmWave communication technologies in the far field. More work may be required to determine the possible effects from exposure above $10 \mathrm{~mW} / \mathrm{cm}^{2}$ that might be experienced in the near field from specific communication devices with adaptive antennas as well as to ensure that mechanisms are in place to ensure that no hazardous levels of energy are transmitted into the eyes. We also showed that using typical power levels, there would be no unsafe temperature increase caused by exposure of skin to mmWave communication technologies in the far field. As with the eyes, however, more work is required to determine temperature increases from higher exposure levels that might be experienced in the near field from specific communication devices with high-gain antennas and to develop and demonstrate reliable mechanisms to ensure that no hazardous levels of energy are transmitted to the skin.

A number of studies of the effects at the cellular and molecular levels of mmWave interactions with biological organisms are summarized. Many of these effects are purportedly at such low levels of exposure that no appreciable temperature increase is expected. A limited number of studies shows that there may be some sensitivity of cell membranes to mmWave exposure, but little is known about this phenomenon and any potential safety repercussions. At this time, more reports of beneficial effects than detrimental effects from low-level exposure to mmWave radiation appear to exist in the literature, but this area needs to be better understood, and the specific effects need to be demonstrated reproducibly by independent investigators before any potential nonthermal effects are to be considered in determining the regulatory limits on this regime of nonionizing radiation [16], [17].

The available data regarding exposure to mmWave energy and the scrutiny of it will continue to increase in the future, as now thousands of travelers are exposed to low-level mmWave radiation during airport security screenings throughout the United States. If the history of studies regarding exposure to nonionizing radiation is a guide, it may have either helpful [83] or harmful [47]-[52] effects in specific exposures much higher than those to which the general public is exposed. Also, as the exposure of the general public to each frequency band increases, individual studies reporting biological effects levels at or below those allowed for the general public will likely receive increased attention, but demonstration of consistently repeatable results at such low levels may be challenging [109].

At a PD of $10 \mathrm{~W} / \mathrm{m}^{2}$, no adverse effects are expected in the eyes or skin. A safety evaluation of a particular device in close proximity to the head or body will require both more sophisticated models than those used here and, most likely, a quantity other than PD for 
characterization of exposure since PD relies simply on far-field concepts. Depending on the predicted exposure levels from specific devices very near human tissues, further experiments to better characterize thresholds for damage, especially in the eyes, may be useful to assure long-term safety.

\section{References}

1. Pi Z, Khan F. An introduction to millimeter-wave mobile broadband systems. IEEE Commun. Mag. 2011; 49(6):101-107.

2. Rappaport TS, Murdock JN, Gutierrez F. State of the art in 60-GHz integrated circuits and systems for wireless communications. Proc. IEEE. Aug.2011 99(8):1390-1436.

3. Rappaport TS, Sun S, Mayzus R, Zhao H, Azar Y, Wang K, Wong GN, Schulz JK, Samimi M, Gutierrez F. Millimeter wave mobile communications for 5G cellular: It will work! IEEE Access. 2013; 1(1):335-349.

4. The Brooklyn 5G Summit. Aug.. 2014 [Online]. Available: http://www.brooklyn5gsummit.com

5. Status of IEEE 802.11 NG60 Study Group. Aug.. 2014 [Online]. Available: http:// www.ieee802.org/11/Reports/ng60_update.htm

6. Pakhomov AG, Akyel Y, Pakhomova ON, Stuck BE, Murphy MR. Current state and implications of research on biological effects of millimeter waves. Bioelectromagnetics. 1998; 19(7):393-413. [PubMed: 9771583]

7. Schwan HP, Foster KR. RF-field interactions with biological systems: Electrical properties and biophysical mechanisms. Proc. IEEE. Jan.1980 68(1):104-113.

8. Furia L, Hill DW, Gandhi OP. Effect of millimeter-wave irradiation on growth of Saccharomyces cerevisiae. IEEE Trans. Biomed. Eng. Nov.1986 BME-33(11):993-999. [PubMed: 3539765]

9. IEEE Standard for Safety Levels with Respect to Human Exposure to the Radio Frequency Electromagnetic Fields, $3 \mathrm{kHz}$ to $300 \mathrm{GHz}$. 1992. IEEE Standard C95.1

10. IEEE Standard for Safety Levels with Respect to Human Exposure to the Radio Frequency Electromagnetic Fields, $3 \mathrm{kHz}$ to $300 \mathrm{GHz}$. 2005. IEEE Standard C95.1

11. Moulder JE. Risks of exposure to ionizing and millimeter-wave radiation from airport whole-body scanners. Radiat. Res. 2012; 177(6):723-726. [PubMed: 22494369]

12. LeVine, S. The Active Denial System-A Revolutionary, Non-Lethal Weapon for Today's Battlefield. National Defense Univ.; Washington, D.C.: Jun. 2009

13. Pozar, DM. Microwave Engineering. 3rd ed.. Wiley; New York: 2009.

14. Tang, CL. Fundamentals of Quantum Mechanics: For Solid State Electronics and Optics. Cambridge Univ. Press; Cambridge, U.K.: 2005.

15. Brenner DJ, Doll R, Goodhead DT, Hall EJ, Land CE, Little JB, Lubin JH, Preston DL, Preston RJ, Puskin JS, Ron E, Sachs RK, Samet JM, Setlow RB, Zaider M. Cancer risks attributable to low doses of ionizing radiation: Assessing what we really know. Proc. Natl. Acad. Sci. U.S. Nov. 2003 100(24):13761-13766.

16. ICNIRP. Guidelines for limiting exposure to time-varying electric, magnetic, and electromagnetic fields (up to $300 \mathrm{GHz}$ ). Health Phys. Apr.1998 74(4):494-522. [PubMed: 9525427]

17. Guidelines for Evaluating the Environmental Effects of Radiofrequency Radiation. Federal Communications Commission; Washington, D.C.: Aug.. 1996

18. Collins CM, Liu W, Wang J, Gruetter R, Vaughan JT, Ugurbil K, Smith MB. Temperature and SAR calculations for a human head within volume and surface coils at 64 and $300 \mathrm{MHz}$. J. Magn. Reson. Imaging. 2004; 19(5):650-656. [PubMed: 15112317]

19. Rappaport, TS. Wireless Communications: Principles and Practice. 2nd ed.. Prentice Hall; Englewood Cliffs, NJ: 2002.

20. Evaluating Compliance with FCC Guidelines for Human Exposure to Radiofrequency Electromagnetic Fields. Federal Communications Commission Standard, OFT Bulletin 65, Edition 97-01. 
21. Brodkin RH, Bleiberg J. Cutaneous microwave injury. A report of two cases. Acta Derm.Venereol. 1973; 53(1):50-52. [PubMed: 4120808]

22. Ciano M, Burlin JR, Pardoe R, Mills RL, Hentz VR. High-frequency electromagnetic radiation injury to the upper extremity: Local and systemic effects. Ann. Plast. Surg. 1981; 7(2):128-135. [PubMed: 7294659]

23. Alekseev SI, Ziskin MC. Millimeter wave power density in aqueous biological samples. Bioelectromagnetics. May; 2001 22(4):288-291. [PubMed: 11298391]

24. Riu PJ, Foster KR, Blick DW, Adair ER. A thermal model for human thresholds of microwaveevoked warmth sensations. Bioelectromagnetics. 1998; 18(8):578-583. [PubMed: 9383246]

25. de Lorge JO, Ezell CS. Observing-responses of rats exposed to 1.28- and 5.62-GHz microwaves. Bioelectromagnetics. 1980; 1(2):183-198. [PubMed: 7284023]

26. de Lorge JO. Operant behavior and colonic temperature of Macaca mulatta exposed to radio frequency fields at and above resonant frequencies. Bioelectromagnetics. 1984; 5(2):233-246. [PubMed: 6732879]

27. Ryan KL, D'Andrea JA, Jauchem JR, Mason PA. Radio frequency radiation of millimeter wave length: Potential occupational safety issues relating to surface heating. Health phys. 2000; 78(2): 170-181. [PubMed: 10647983]

28. Yarmolenko PS, Moon EJ, Landon C, Manzoor A, Hochman DW, Viglianti BL, Dewhirst MW. Thresholds for thermal damage to normal tissue: An update. Int. J. Hyperthermia. 2011; 27(4): 320-343. [PubMed: 21591897]

29. Ma, JG., editor. Third Generation Communication Systems: Future Developments and Advanced Topics. Springer; Berlin, Germany: 2004.

30. Foster KR, Vecchia P, Repacholi MH. Risk management: Science and the precautionary principle. Science. 2000; 288(5468):979-981. [PubMed: 10841718]

31. Bielski J. Bioelectrical brain activity in workers exposed to electromagnetic fields. Ann. New York Acad. Sci. 1994; 724(1):435-437. [PubMed: 8030972]

32. Chiang, H. Rationale for setting EMF exposure standards. Jun. 2014 [Online]. Available: http:// www.salzburg.gv.at/Proceedings_(20)_Chiang.pdf

33. Standards. Jul. 2014 [Online]. Available: http://www.tesla.ru/english/protection/standards.html

34. Ordinance relating to protection from non-ionising radiation. Jun. 2014 [Online]. Available: http:// www.bafu.admin.ch/elektrosmog/01100/01101/index.html?lang=fr

35. EMF policy facts: Switzerland. presented at Second Mobile Communications Seminar; Résidence Palace, Brussels, Belgium. Sept. 2004;

36. Establishment of exposure limits, attention values, and quality goals to protect the population against electric, magnetic, and electromagnetic fields generated at frequencies between $100 \mathrm{kHz}$ and $300 \mathrm{GHz}$. Jun. 2014 [Online]. Available: http://www.who.int/docstore/peh-emf/ EMFStandards/who-0102/Europe/Italy_files/table_datoteke/Italy_DPCM_RF_eng.pdf

37. Standards and guidelines. Aug.. 2014 [Online]. Available: http://www.who.int/peh-emf/ standards/en/

38. Lin JC. Safety standards for human exposure to radio frequency radiation and their biological rationale. IEEE Microwave Mag. Dec.2003 4(4):22-26.

39. Emami S, Wiser RF, Ali E, Forbes MG, Gordon MQ, Guan X, Lo S, McElwee PT, Parker J, Tani JR, Gilbert JM, Doan CH. A $60 \mathrm{GHz}$ CMOS phased-array transceiver pair for multi-Gb/s wireless communications. 2011 IEEE Int. Solid-State Circuits Conf. Dig. Tech. Papers. Feb.2011:164166.

40. Rappaport, TS.; Health, RW., Jr.; Daniels, RC.; Murdock, JN. Millimeter Wave Wireless Communications. Prentice Hall; Englewood Cliffs, NJ: 2015.

41. Biological Effects and Exposure Criteria for Radiofrequency Electromagnetic Fields. National Council on Radiation Protection and Measurements; Bethesda, MD: 1986. Tech. Rep. 86

42. Zhadobov M, Chahat N, Sauleau R, Le Quément C, Le Dréan Y. Millimeter-wave interactions with the human body: State of knowledge and recent advances. Int. J. Microwave Wireless Technol. Apr.2011 3(2):237-247. 
43. Hall PS, Hao Y, Cotton SL. Advances in antennas and propagation for body centric wireless communications. Proc. 2010 IEEE 4th European Conf. Antennas Propagation. Apr.2010:1-7.

44. Evaluating Compliance with FCC Guidelines for Human Exposure to Radio-frequency Electromagnetic Fields. Federal Communications Commission; Washington, D.C.: 2001. Tech. Rep. Suppl. C to OET Bulletin 65

45. Kues HA, D'Anna SA, Osiander R, Green WR, Monahan JC. Absence of ocular effects after either single or repeated exposure to $10 \mathrm{~mW} / \mathrm{cm}^{2}$ from a $60 \mathrm{GHz} \mathrm{CW}$ source. Bioelectromagnetics. 1999; 20(8):463-473. [PubMed: 10559768]

46. Chalfin S, D'Andrea JA, Comeau PD, Belt ME, Hatcher DJ. Millimeter wave absorption in the nonhuman primate eye at $35 \mathrm{GHz}$ and 94 GHz. Health Phys. Jul; 2000 83(1):83-90. [PubMed: 12075687]

47. Rosenthal SW, Birenbaum L, Kaplan IT, Metlay W, Snyder WZ, Zaret MM. Effects of 35 and 107 GHz CW microwaves on the rabbit eye. Proc. USNC/URSI Annu. Meeting. 1976:110-128.

48. Kojima M, Hanazawa M, Yamashiro Y, Sasaki H, Watanabe S, Taki M, Suzuki Y, Hirata A, Kamimura Y, Sasaki K. Acute ocular injuries caused by $60-\mathrm{GHz}$ millimeter-wave exposure. Health Phys. Sept.2009 97(3):212-218. [PubMed: 19667804]

49. Foster KR, D'Andrea JA, Chalfin S, Hatcher D. Thermal modeling of millimeter wave damage to the primate cornea at $35 \mathrm{GHz}$ and $94 \mathrm{GHz}$. Health Phys. Jun; 2003 84(6):764-769. [PubMed: 12822586]

50. Karampatzakis A, Theodoros S. Numerical model of heat transfer in the human eye with consideration of fluid dynamics of the aqueous humour. Phys. Med. Biol. Sept.2010 55(19):56535665. [PubMed: 20826900]

51. Papaioannou A, Theodoros S. Numerical model of heat transfer in the rabbit eye exposed to 60GHz millimeter wave radiation. IEEE Trans. Biomed. Eng. Sept.2011 58(9):2582-2588. [PubMed: 21672669]

52. Karampatzakis A, Theodoros S. Numerical modeling of heat and mass transfer in the human eye under millimeter wave exposure. Bioelectromagnetics. May; 2013 34(4):291-299. [PubMed: 23315965]

53. Alekseev SI, Ziskin MC. Human skin permittivity determined by millimeter wave reflection measurements. Bioelectromagnetics. 2007; 28(5):331-339. [PubMed: 17429851]

54. Gabriel C, Gabriel S, Corthout E. The dielectric properties of biological tissues: I. Literature survey. Phys. Med. Biol. 1996; 41(11):2231-2249. [PubMed: 8938024]

55. Gabriel S, Lau RW, Gabriel C. The dielectric properties of biological tissues: II. Measurements in the frequency range $10 \mathrm{~Hz}$ to $20 \mathrm{GHz}$. Phys. Med. Biol. 1996; 41(11):2251. [PubMed: 8938025]

56. Gabriel S, Lau RW, Gabriel C. The dielectric properties of biological tissues: III. Parametric models for the dielectric spectrum of tissues. Phys. Med. Biol. 1996; 41(11):2271. [PubMed: 8938026]

57. Gandhi OP, Riazi A. Absorption of millimeter waves by human beings and its biological implications. IEEE Trans. Microwave Theory Tech. Feb.1986 34(2):228-235.

58. Alabaster CM. Permittivity of human skin in millimetre wave band. Electron. Lett. Oct.2003 39(21):1521-1522.

59. Hwang H, Yim J, Cho J-W, Cheon C, Kwon Y. $110 \mathrm{GHz}$ broadband measurement of permittivity on human epidermis using $1 \mathrm{~mm}$ coaxial probe. 2003 IEEE MTT-S Int. Microwave Symp. Dig. Jun.2003 1:399-402.

60. Chahat N, Zhadobov M, Augustine R, Sauleau R. Human skin permittivity models for millimetrewave range. Electron. Lett. Mar.2011 47(7):427-428.

61. Andreuccetti, D.; Fossi, R.; Petrucci, C. An internet resource for the calculation of the dielectric properties of body tissues in the frequency range $10 \mathrm{~Hz}-100 \mathrm{GHz}$. IFAC-CNR; Florence, Italy: 1996. [Online]. Available: http://niremf.ifac.cnr.it/tissprop/

62. Hasgall, PA.; Neufeld, E.; Gosselin, MC.; Klingenböck, A.; Kuster, N. IT'IS database for thermal and electromagnetic parameters of biological tissues. Version 2.5. Aug.. 2014 [Online]. Available: www.itis.ethz.ch/database 
63. Chahat N, Zhadobov M, Le Coq L, Alekseev SI, Sauleau R. Characterization of the interactions between a $60-\mathrm{GHz}$ antenna and the human body in an off-body scenario. IEEE Trans. Antennas Propagat. 2012; 60(12):5958-5965.

64. Gandhi OP. State of the knowledge for electromagnetic absorbed dose in man and animals. Proc. IEEE. 1980; 68(1):24-32.

65. Sullivan DM, Borup DT, Gandhi OP. Use of the finite-difference time-domain method in calculating EM absorption in human tissues. IEEE Trans. Biomed. Eng. 1987; BME-34(2):148157. [PubMed: 3557494]

66. Hirata A, Fujiwara O, Shiozawa T. Correlation between peak spatial-average SAR and temperature increase due to antennas attached to human trunk. IEEE Trans. Biomed. Eng. 2006; 53(8):16581664. [PubMed: 16916100]

67. Foster KR, Kritikos HN, Schwan HP. Effect of surface cooling and blood flow on the microwave heating of tissue. IEEE Trans. Biomed. Eng. May; 1978 BME-25(3):313-316. [PubMed: 680769]

68. Walters TJ, Blick DW, Johnson LR, Eleanor ER, Foster KR. Heating and pain sensation produced in human skin by millimeter waves: Comparison to a simple thermal model. Health Phys. Mar. 2000 78(3):259-267. [PubMed: 10688448]

69. Alekseev SI, Ziskin MC. Influence of blood flow and millimeter wave exposure on skin temperature in different thermal models. Bioelectromagnetics. 2009; 30(1):52-58. [PubMed: 18780297]

70. Alekseev SI, Radzievsky AA, Szabo I, Ziskin MC. Local heating of human skin by millimeter waves: Effect of blood flow. Bioelectromagnetics. 2005; 26(6):489-501. [PubMed: 15931684]

71. Nelson DA, Nelson MT, Walters TJ, Mason PA. Skin heating effects of millimeter-wave irradiation-thermal modeling results. IEEE Trans. Microwave Theory Tech. Nov.2000 48(11): 2111-2120.

72. Kanezaki A, Watanabe S, Hirata A, Shirai H. Theoretical analysis for temperature elevation of human body due to millimeter wave exposure. Proc. IEEE Biomedical Engineering Conf. Dec. $2008: 1-4$.

73. Pennes HH. Analysis of tissue and arterial blood temperatures in the resting human forearm. J. Appl. Physiol. Aug.1948 85(1):5-34. [PubMed: 9714612]

74. Kanezaki A, Hirata A, Watanabe S, Shirai H. Parameter variation effects on temperature elevation in a steady-state, one-dimensional thermal model for millimeter wave exposure of one-and threelayer human tissue. Phys. Med. Biol. 2010; 55(16):4647. [PubMed: 20671356]

75. Chahat N, Zhadobov M, Sauleau R. Broadband tissue-equivalent phantom for BAN applications at millimeter waves. IEEE Trans. Microwave Theory Tech. Jul; 2012 60(7):2259-2266.

76. Zilberti L, Arduino A, Bottauscio O, Chiampi M. A model to analyze the skin heating produced by millimeter and submillimeter electromagnetic waves. Proc. IEEE Int. Conf. Electromagnetics Advanced Applications. Sept.2013:895-898.

77. Zilberti L, Arduino A, Bottauscio O, Chiampi M. Parametric analysis of transient skin heating induced by terahertz radiation. Bioelectromagnetics. Jul; 2014 35(5):314-323. [PubMed: 24510310]

78. Harmer SW, Rezgui N, Bowring N, Luklinska Z, Ren G. Determination of the complex permittivity of textiles and leather in the $14-40 \mathrm{GHz}$ millimetre-wave band using a free-wave transmittance only method. IET Microwaves, Antennas Propagat. 2008; 2(6):606-614.

79. Bjarnason JE, Chan TLJ, Lee AWM, Celis MA, Brown ER. Millimeter-wave, terahertz, and midinfrared transmissionthrough common clothing. Appl. Phys. Lett. 2004; 85(4):519-521.

80. Gatesman AJ, Danylov A, Goyette TM, Dickinson JC, Giles RH, Goodhue W, Waldman J, Nixon WE, Hoen W. Terahertz behavior of optical components and common materials. Proc. Int. Society Optics Photonics Defense Security Symp. May.2006 :62120E-62120E.

81. Vallozzi L, Vandendriessche W, Rogier H, Hertleer C, Scarpello ML. Wearable textile GPS antenna for integration in protective garments. Proc. IEEE 2010 4th European Conf. Antennas Propagation. 2010:1-4.

82. Khan MM, Abbasi QH, Alomainy A, Parini C, Hao Y. Dual band and diverse radiation pattern antenna for power efficient and reliable on-body and off-body communications for healthcare applications. Proc. IEEE Int. Symp. Antennas Propagation. 2011:396-399. 
83. Wust P, Hildebrandt B, Sreenivasa G, Rau B, Gellermann J, Riess H, Felix R, Schlag PM. Hyperthermia in combined treatment of cancer. Lancet Oncol. 2002; 3(8):487-497. [PubMed: 12147435]

84. Wireless devices and health concerns. Jun. 2014 [Online]. Available: http://www.fcc.gov/guides/ wireless-devices-and-health-concerns

85. Electromagnetic fields and public health: Mobile phones. Sept.. 2014 [Online]. Available: http:// www.who.int/mediacentre/factsheets/fs 193/en/

86. Lebedeva, NN.; Betskii, OV. Proc. BEMS 17th Annu. Meeting. Boston, MA: 1995. Application of low intensity millimeter waves in medicine; p. 14

87. Banik S, Bandyopadhyay S, Ganguly S. Bioeffects of microwave-A brief review. Bioresour. Technol. 2003; 87(2):155-159. [PubMed: 12765354]

88. Pakhomov AG, Murthy PR. Low-intensity millimeter waves as a novel therapeutic modality. IEEE Trans. Plasma Sci. Feb.2000 28(1):34-40.

89. Chatterjee I, Yoon J, Wiese R, Luongo S, Mastin P, Sadovnik L, Craviso GL. Millimeter wave bioeffects at $94 \mathrm{GHz}$ on skeletal muscle contraction. Proc. IEEE Topical Conf. Biomedical Wireless Technologies, Networks, Sensing Systems (BioWireleSS). Jan.2013:67-69.

90. Ziskin MC. Physiological mechanisms underlying millimeter wave therapy. Bioelectromagnetics. 2006:241-251.

91. Gos P, Eicher B, Kohli J, Heyer W-D. Extremely high frequency electromagnetic fields at low power density do not affect the division of exponential phase Saccharomyces cerevisiae cells. Bioelectromagnetics. 1997; 18(2):142-155. [PubMed: 9084865]

92. Logani MK, Bhanushali A, Ziskin MC, Prihoda TJ. Micronuclei in peripheral blood and bone marrow cells of mice exposed to $42 \mathrm{GHz}$ electromagnetic millimeter waves. Radiat. Res. 2004; 161(3):341-345. [PubMed: 14982479]

93. Le Quément C, Nicolaz CN, Zhadobov M, Desmots F, Sauleau R, Aubry M, Michel D, Le Dréan Y. Whole-genome expression analysis in primary human keratinocyte cell cultures exposed to 60 GHz radiation. Bioelectromagnetics. 2012; 33(2):147-158. [PubMed: 21812010]

94. Zhadobov M, Sauleau R, Le Coq L, Debure L, Thouroude D, Michel D, Le Dréan Y. Low-power millimeter wave radiations do not alter stress-sensitive gene expression of chaperone proteins. Bioelectromagnetics. 2007; 28(3):188-196. [PubMed: 17080454]

95. Beneduci A, Chidichimo G, De Rose R, Filippelli L, Straface SV, Venuta S. Frequency and irradiation time-dependant antiproliferative effect of low-power millimeter waves on RPMI 7932 human melanoma cell line. Anticancer Res. Mar.2005 25(2A):1023-1028. [PubMed: 15868942]

96. Radzievsky AA, Gordiienko OV, Szabo I, Alekseev SI, Ziskin MC. Millimeter wave-induced suppression of B16 F10 melanoma growth in mice: Involvement of endogenous opioids. Bioelectromagnetics. Sept.2004 25(6):466-473. [PubMed: 15300733]

97. Logani MK, Szabo I, Makar V, Bhanushali A, Alekseev S, Ziskin MC. Effect of millimeter wave irradiation on tumor metastasis. Bioelectromagnetics. 2006; 27(4):258-264. [PubMed: 16437545]

98. Le Dréan Y, Mahamoud YS, Le Page Y, Habauzit D, Le. Quément C, Zhadobov M, Sauleau R. State of knowledge on biological effects at 40-60 GHz. Comptes Rendus Physique. May; 2013 14(5):402-411.

99. Zhadobov M, Sauleau R, Vie V, Himdi M, Le Coq L, Thouroude D. Interactions between 60-GHz millimeter waves and artificial biological membranes: Dependence on radiation parameters. IEEE Trans. Microwave Theory Tech. 2006; 54(6):2534-2542.

100. Szabo I, Kappelmayer J, Alekseev SI, Ziskin MC. Millimeter wave induced reversible externalization of phosphatidylserine molecules in cells exposed in vitro. Bioelectromagnetics. 2006; 27(3):233-244. [PubMed: 16437546]

101. Ramundo-Orlando A, Longo G, Cappelli M, Girasole M, Tarricone L, Beneduci A, Massa R. The response of giant phospholipid vesicles to millimeter waves radiation. Biochimica et Biophysica Acta (BBA)-Biomembranes. Jul; 2009 1788(7):1497-1507. [PubMed: 19376085]

102. Ramundo-Orlando A, Gallerano GP, Stano P, Doria A, Giovenale E, Messina G, Cappelli M, D'Arienzo M, Spassovsky I. Permeability changes induced by $130 \mathrm{GHz}$ pulsed radiation on cationic liposomes loaded with carbonic anhydrase. Bioelectromagnetics. 2007; 28(8):587-598. [PubMed: 17620303] 
103. Rojavin MA, Ziskin MC. Medical application of millimetre waves. Q. J. Med. 1998; 91(1):57-66.

104. Makar V, Logani M, Szabo I, Ziskin M. Effect of millimeter waves on cyclophosphamide induced suppression of T cell functions. Bioelectromagnetics. 2003; 24(5):356-365. [PubMed: 12820293]

105. Makar V, Logani M, Szabo I, Ziskin M. Effect of millimeter waves on natural killer cell activation. Bioelectromagnetics. Jul; 2005 26(1):10-19. [PubMed: 15605409]

106. Gapeyev AB, Mikhailik EN, Chemeris NK. Anti-inflammatory effects of low-intensity extremely high-frequency electromagnetic radiation: Frequency and power dependence.

Bioelectromagnetics. Apr.2008 29(3):197-206. [PubMed: 18044738]

107. Gapeyev AB, Mikhailik EN, Chemeris NK. Features of anti-inflammatory effects of modulated extremely high-frequency electromagnetic radiation. Bioelectromagnetics. Sept.2009 30(6):454461. [PubMed: 19431156]

108. Particular Requirements for the Basic Safety and Essential Performance of Magnetic Resonance Equipment for Medical Diagnosis. 2010. IEC Standard 60601-2-33

109. Foster KR, Pickard WF. Microwaves: The risks of risk research. Nature. Dec.1987 330:531-532. [PubMed: 3683571] 
MmWave radiation is nonionizing because the photon energy is not nearly sufficient to remove an electron from an atom or a molecule. 
PD is not as useful as SAR or temperature for assessing safety in mmWave devices, especially in the near field. 
The FCC and ICNIRP standards are designed principally to protect against thermal hazards since ionizing radiation is not a concern at mmWave frequencies. 
At mmWave frequencies, where most of the energy is absorbed in the few outer millimeters of tissue, even a 1-g averaging volume can seem large. 
We suggest that performing temperature elevation measurements for the compliance evaluation of mmWave wireless devices operating very close to the human body. 
The eyes are particularly vulnerable to mmWave radiation-induced heating. 
MmWave attenuation of most garment materials is negligible.

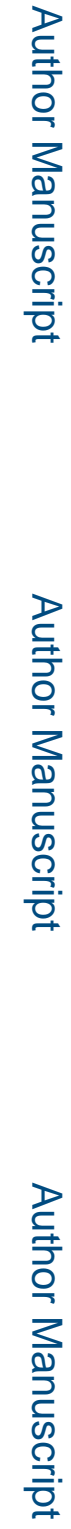


Further measurements of dielectric permittivity on different body sites and different human subjects are warranted to characterize the variability and distribution of properties for the development of accurate human models. 
Major decisions on public policy or health care should not typically be made based on reports that were not reproduced independently. 


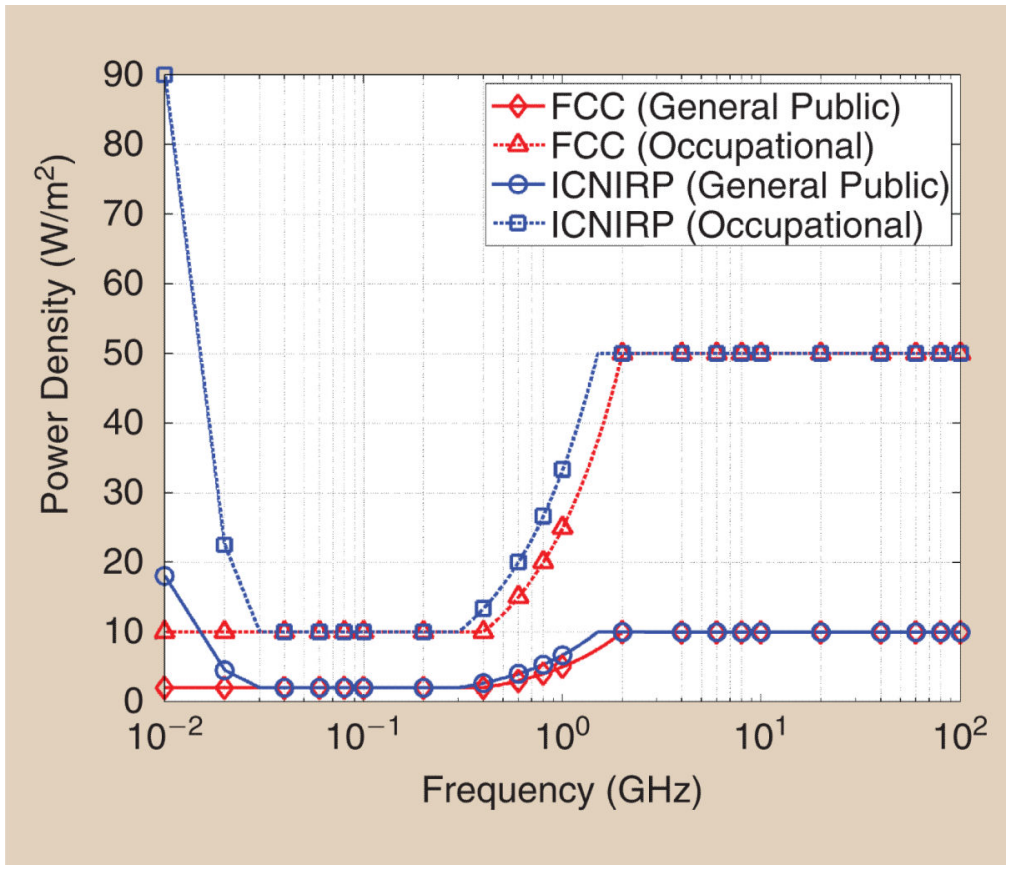

Figure 1.

The FCC and ICNIRP PD restrictions for electromagnetic wave exposure from $10 \mathrm{MHz}$ to $100 \mathrm{GHz}$. 


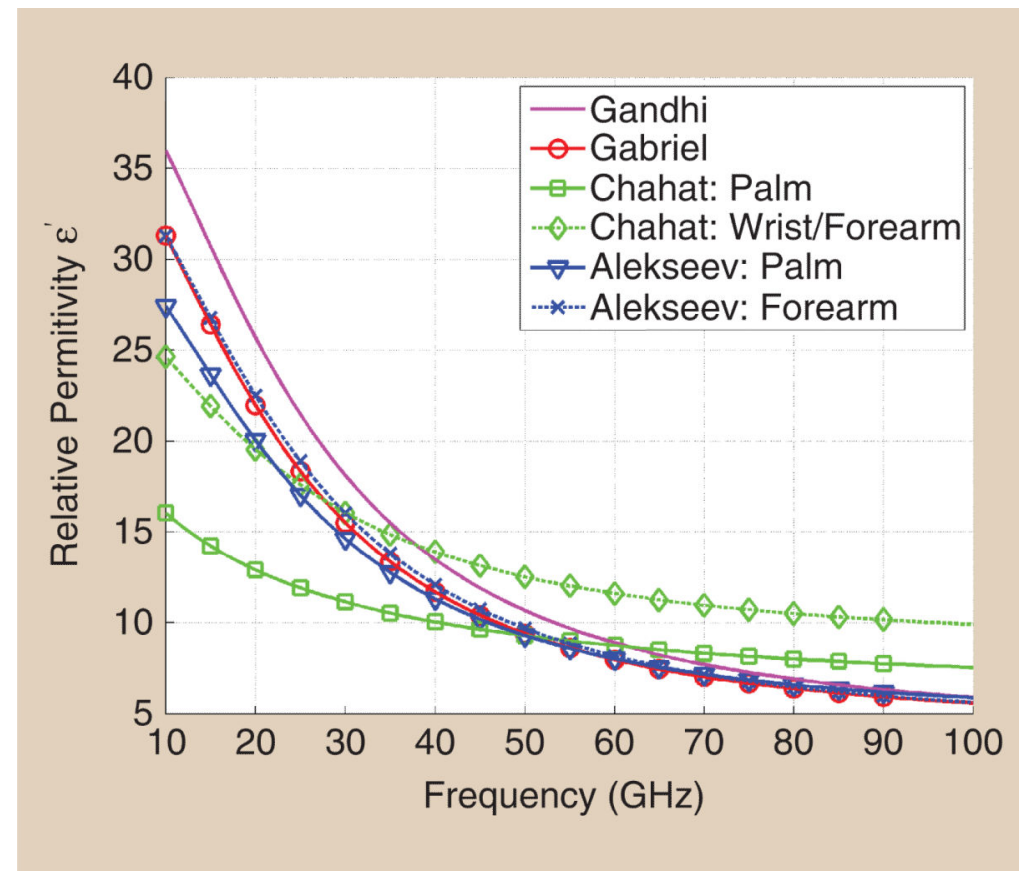

Figure 2.

The predicted skin relative permittivity according to model parameters presented by several researchers from 10 to $100 \mathrm{GHz}$. 


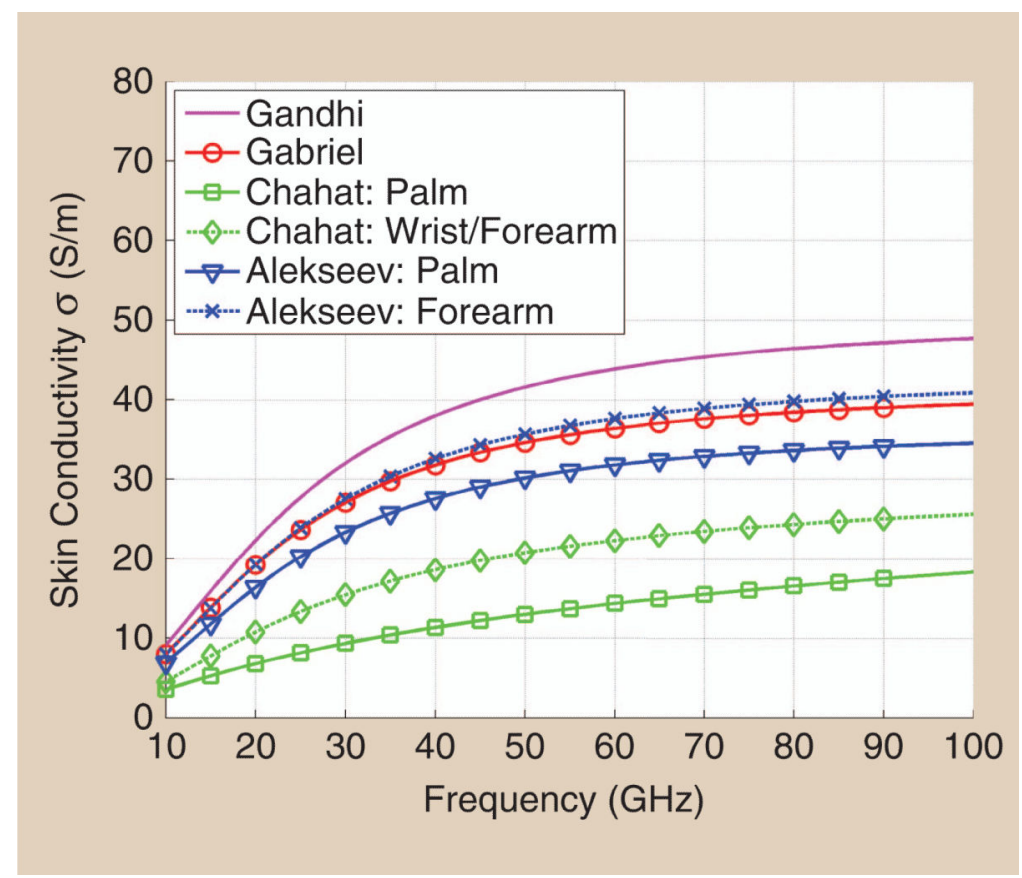

Figure 3.

The predicted skin conductivity according to model parameters presented by several researchers from 10 to $100 \mathrm{GHz}$. 


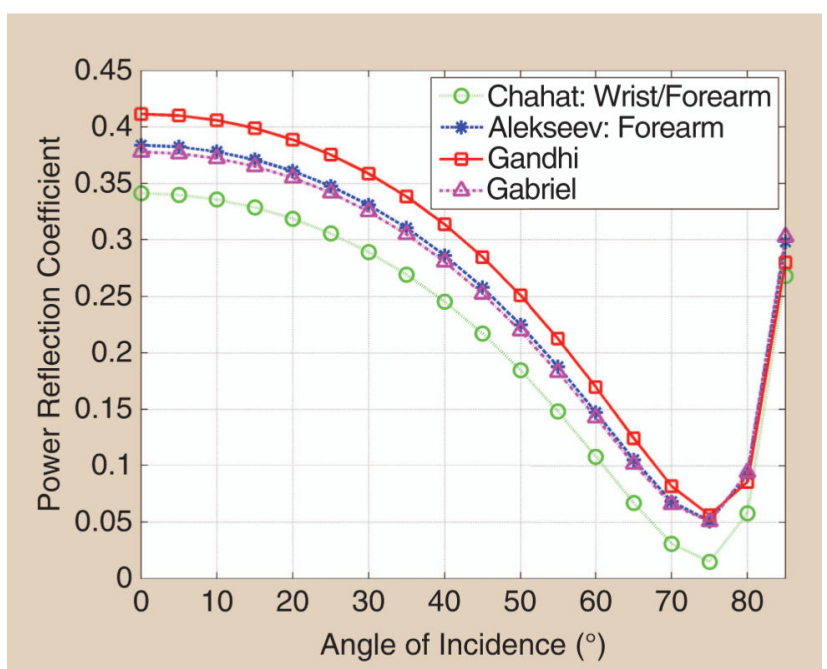

(a)

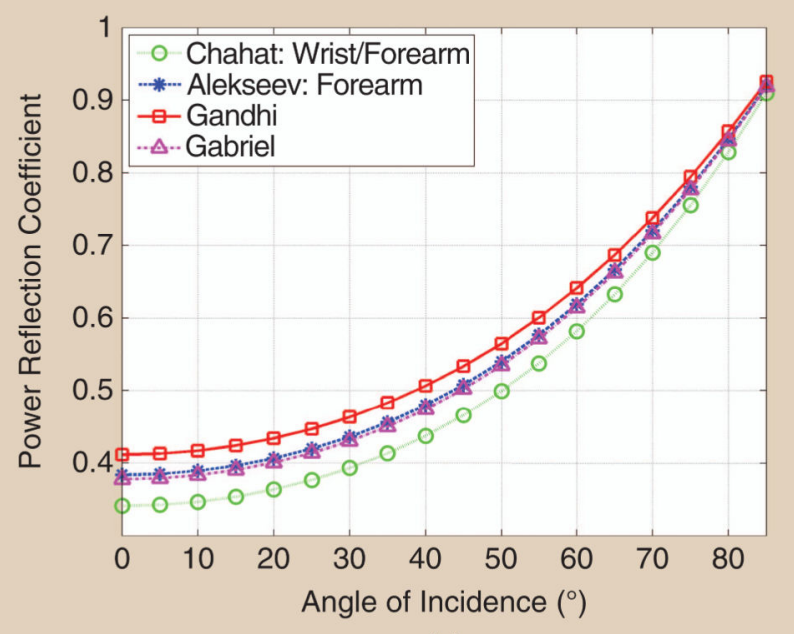

(b)

Figure 4.

The power reflection coefficients at the air/skin interface at $60 \mathrm{GHz}$ using different skin model parameters for (a) parallel polarization and (b) perpendicular polarization. 


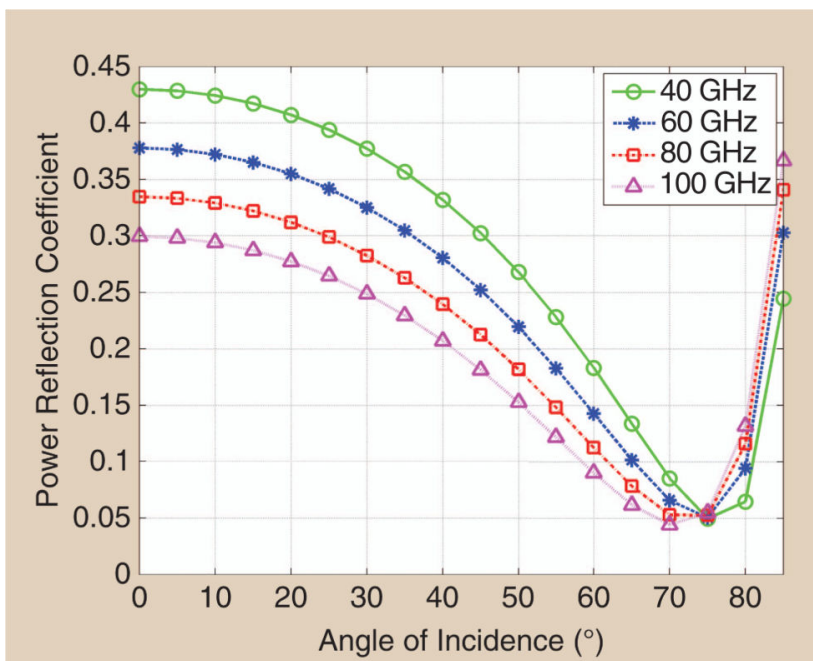

(a)

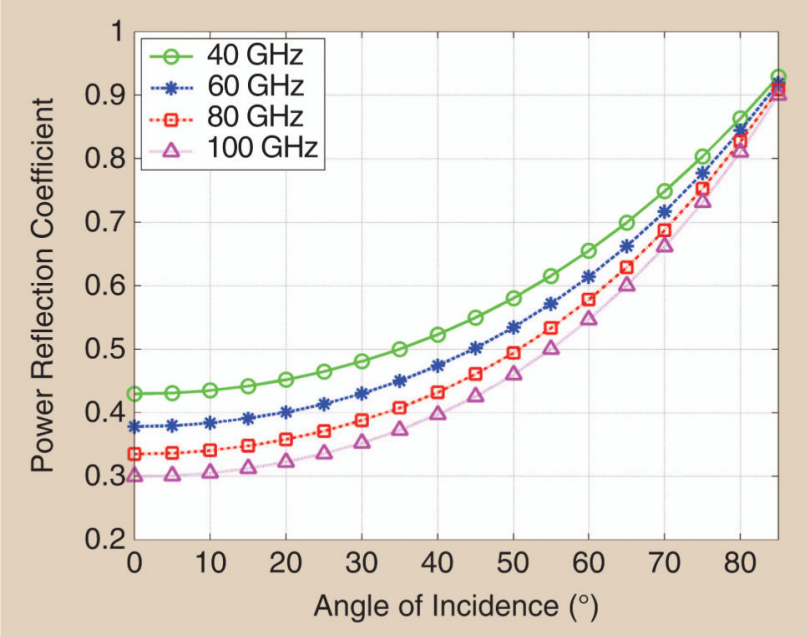

(b)

Figure 5.

The power reflection coefficients at the air/skin interface using Gabriel's skin model at 40, 60,80 , and $100 \mathrm{GHz}$ for (a) parallel polarization and (b) perpendicular polarization. 


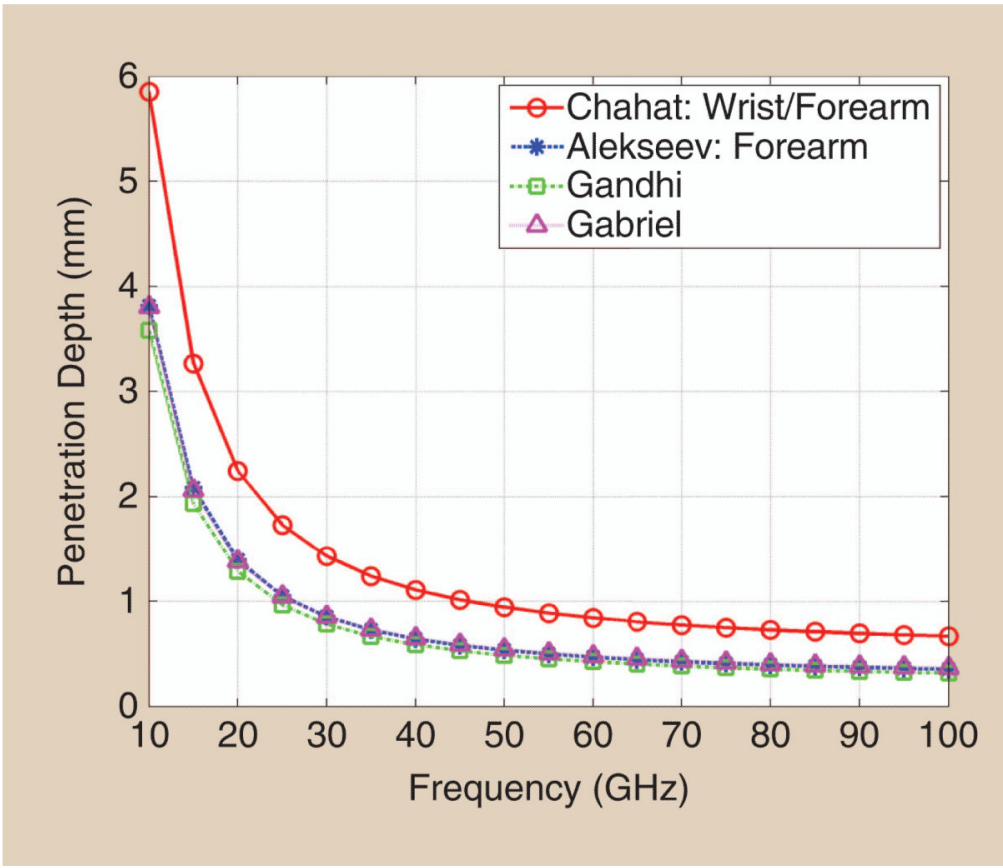

Figure 6.

The penetration depth in the human skin with the increase of exposure frequency. 


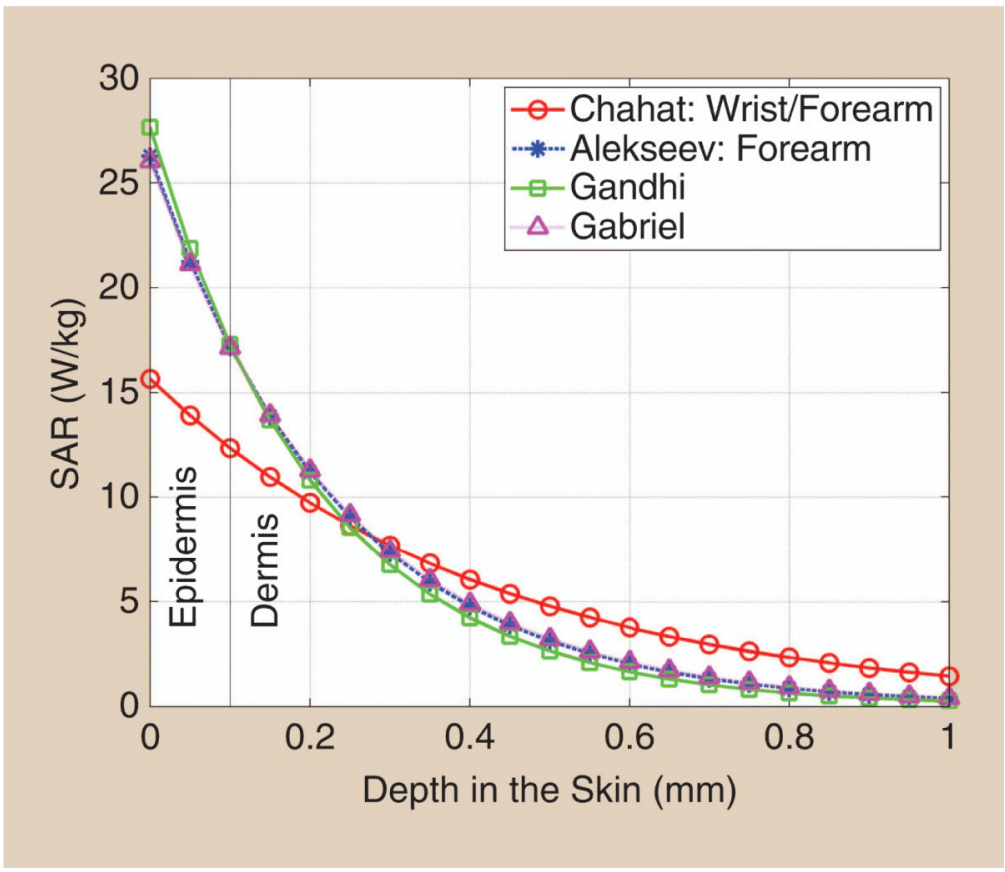

Figure 7.

The attenuation of SAR in the skin for an incident PD of $10 \mathrm{~W} / \mathrm{m}^{2}$ at $60 \mathrm{GHz}$. 


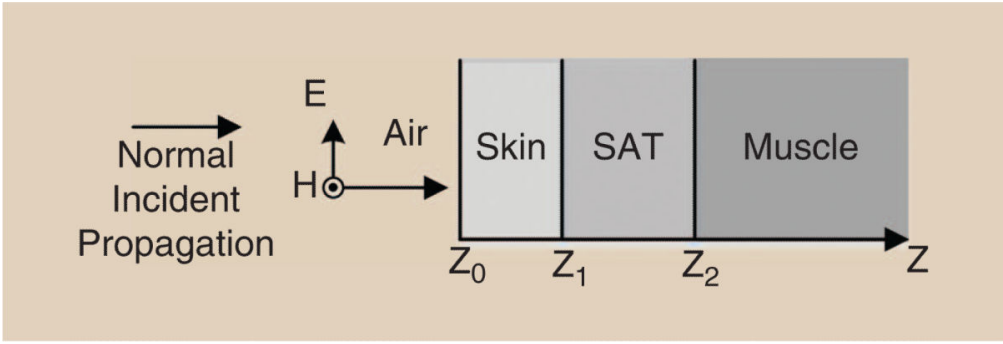

Figure 8.

A 1-D three-layer model of human tissue containing skin, SAT, and muscle. 


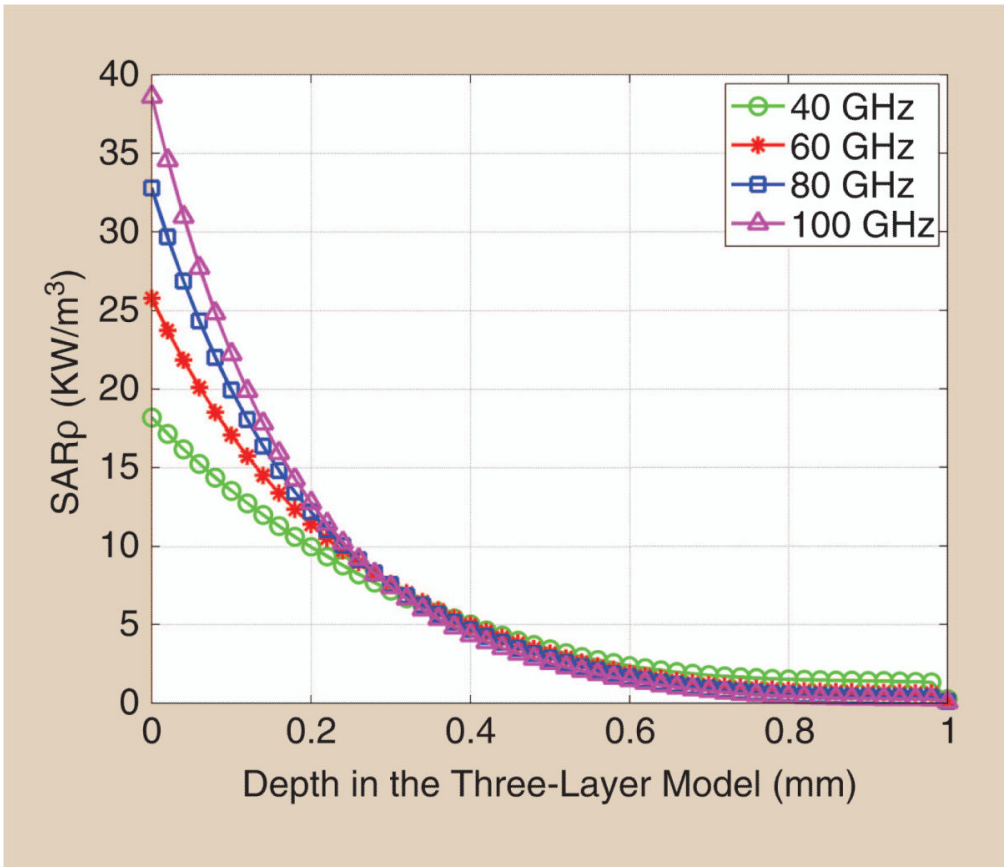

Figure 9.

The SAR $\rho$ distribution due to $10 \mathrm{~W} / \mathrm{m}^{2} \mathrm{mmWave}$ radiation at 40, 60, 80, and $100 \mathrm{GHz}$. 


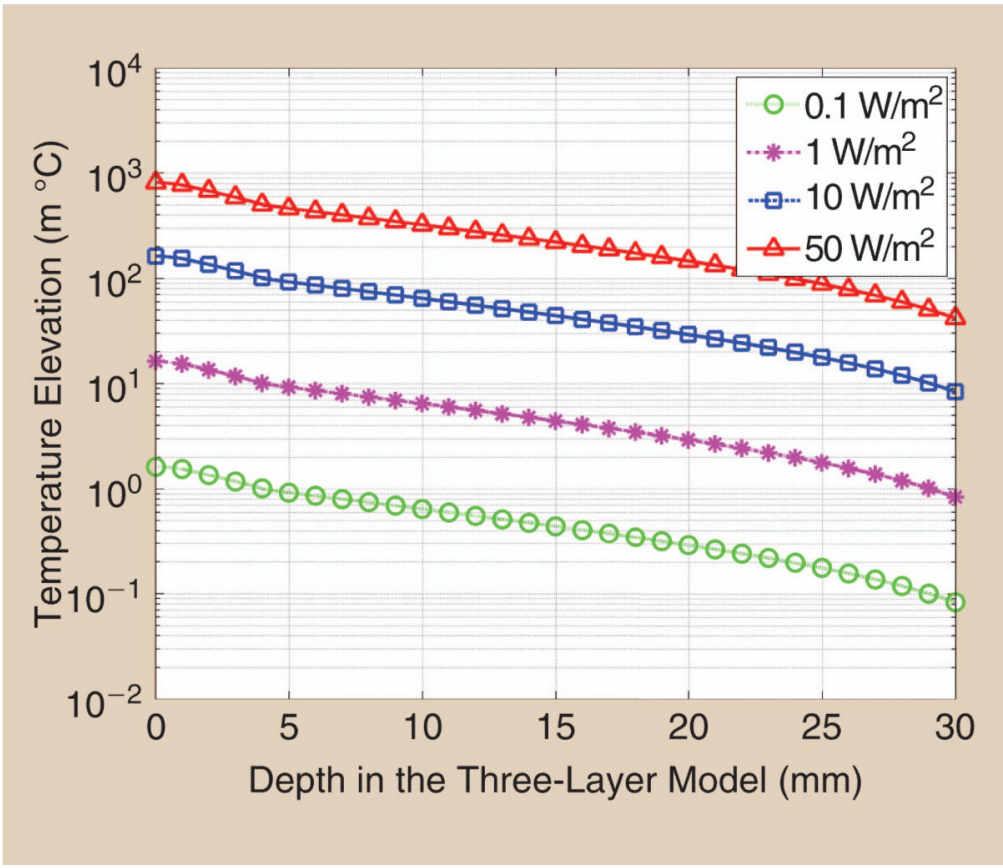

Figure 10.

The steady-state temperature elevation in the three-layer human tissue model at $60 \mathrm{GHz}$ with different incident power densities. 


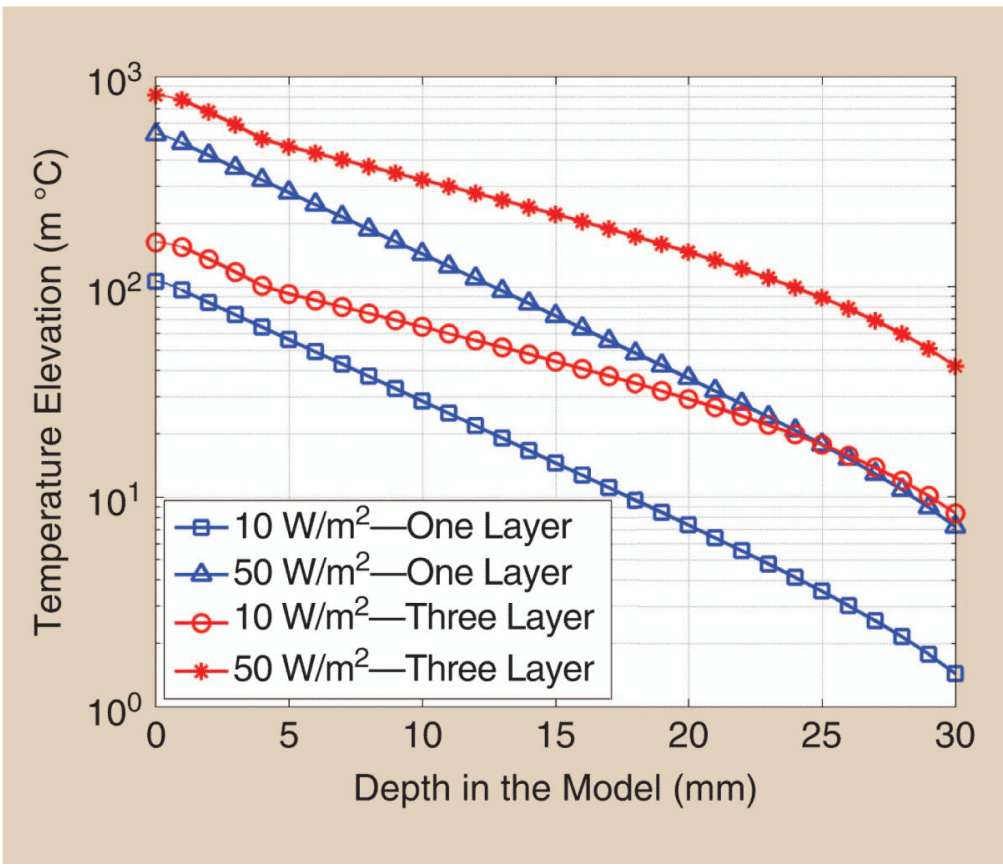

Figure 11.

The steady-state temperature elevation at incident power densities of 10 and $50 \mathrm{~W} / \mathrm{m}^{2}$ due to $60-\mathrm{GHz}$ electromagnetic wave exposure for a three-layer model and a one-layer model that consists of skin only. 


\section{TABLE 1}

The variations of exposure limits to RF radiation in several countries.

\begin{tabular}{|c|c|c|c|c|}
\hline Country/Guidelines & $\begin{array}{l}\text { PD Restrictions for } \\
\text { the General Public } \\
\text { in } W / \mathrm{m}^{2}\end{array}$ & $\begin{array}{l}\text { PD Restrictions for } \\
\text { the General Public } \\
\text { in } \mathrm{mW} / \mathrm{cm}^{2}\end{array}$ & Frequency Range (GHz) & Basis \\
\hline ICNIRP [17] (1998) & 10 & 1 & $2-300$ & Science based \\
\hline FCC [16] (1996) & 10 & 1 & $1.5-100$ & Science based \\
\hline China [32] (1987) ${ }^{*}$ & 0.1 & 0.01 & $0.3-300$ & Science based \\
\hline Russia [33] (2003) & 0.1 & 0.01 & $0.3-300$ & Science based \\
\hline Switzerland [34] and [35] (2000) ${ }^{*}$ & 0.1 & 0.01 & $1.8-300$ & Precautionary \\
\hline Italy [36] $(2003)^{*}$ & 0.1 & 0.01 & $0.0001-300$ & Precautionary \\
\hline $\begin{array}{l}\text { Typical maximum exposure from cellular } \\
\text { base station mounted on } 50 \text {-m tower } \\
\text { (assuming a total effective radiated power } \\
\text { of } 2,500 \mathrm{~W} \text { in each sector, summed over } \\
\text { all channels) }\end{array}$ & 0.01 & 0.001 & $1-2$ & Example from [29] \\
\hline
\end{tabular}


TABLE 2

A comparison of the FCC and ICNIRP local SAR limits in the head and trunk for the general public.

\begin{tabular}{llll}
\hline Exposure Standard & $\begin{array}{l}\text { SAR Limits for Near- } \\
\text { Field RF Exposure } \\
\text { (W/kg) }\end{array}$ & Frequency Range (MHz) & Averaging Volume \\
\hline ICNIRP & 2 & $10-10,000$ & "any 10 g of contiguous tissue" (10-g SAR) \\
FCC & 1.6 & $0.1-6,000$ & $\begin{array}{l}\text { "any 1 g of tissue, defined as a tissue volume in the shape of } \\
\text { a cube" (1-g SAR) }\end{array}$ \\
\hline
\end{tabular}


Table 3

FCC compliance evaluation criteria used for different exposure scenarios [44].

\begin{tabular}{lll}
\hline Frequency $(\mathbf{G H z})$ & Distance Between Radiation Sources and the Human Body $(\mathbf{c m})$ & Criterion \\
\hline$<6$ & $<20$ & SAR \\
$<6$ & $<20$ & PD (direct measurements) \\
$>6$ & $>5$ & PD (direct measurements) \\
$>6$ & $<5$ & PD (numerical modeling) \\
\hline
\end{tabular}


TABLE 4

The summary of ocular damage caused by mmWave radiation.

\begin{tabular}{|c|c|c|c|c|c|}
\hline Author & Study Target & Frequency $(\mathbf{G H z})$ & $\mathrm{PD}\left(\mathrm{mW} / \mathrm{cm}^{2}\right)$ & Duration & Results \\
\hline Rosenthal et al. [47] & Rabbit eyes & $35 / 107$ & 50 & $15-80 \mathrm{~min}$ & $\begin{array}{l}\text { Transient corneal damage, began to } \\
\text { recover on the next day }\end{array}$ \\
\hline Kues et al. [45] & Nonhuman primate eyes & 60 & 10 & $8 \mathrm{~h}$ & No detectable ocular damage \\
\hline Chalfin et al. [46] & Nonhuman primate eyes & 35 & $2,000-7,000$ & $1.5-5 \mathrm{~s}$ & $\begin{array}{l}\text { Transient corneal lesions, reversible } \\
\text { within } 24 \mathrm{~h}\end{array}$ \\
\hline Kojima et al. [48] & Rabbit eyes & 60 & 1,898 & $6 \min$ & Corneal edema and desiccation \\
\hline
\end{tabular}


TABLE 5

The Debye and Cole-Cole relaxation model [56].

\begin{tabular}{ll}
\hline Model & Relative Complex Permittivity $\varepsilon^{\prime}-j \varepsilon^{\prime \prime}$ \\
\hline Single-term Debye & $\mathcal{E}_{\infty}+\frac{\varepsilon_{s}-\varepsilon_{\infty}}{1+j \omega \tau}+\frac{\sigma_{s}}{j \omega \varepsilon_{0}}$ \\
Multiple-term Debye & $\mathcal{E}_{\infty}+\sum_{n} \frac{\Delta \varepsilon_{n}}{1+j \omega \tau_{n}}+\frac{\sigma_{s}}{j \omega \varepsilon_{o}}$ \\
Single-term Cole-Cole & $\varepsilon_{\infty}+\frac{\varepsilon_{s}-\varepsilon_{\infty}}{1+(j \omega \tau)^{1-a}}+\frac{\sigma_{s}}{j \omega \varepsilon_{o}}$ \\
Multiple-term Cole-Cole & $\varepsilon_{\infty}+\sum_{n} \frac{\Delta \varepsilon_{n}}{1+\left(j \omega \tau_{n}\right)^{1-a_{n}}+\frac{\sigma_{s}}{j \omega \varepsilon_{o}}}$
\end{tabular}




\section{TABLE 6}

The summary of skin permittivity parameters in single Debye and Cole-Cole models developed by different researchers.

\begin{tabular}{llllll}
\hline Author & $\varepsilon_{\infty}$ & $\varepsilon_{S}$ & $\tau(\mathbf{p s})$ & $\sigma_{S}(\mathbf{S} / \mathbf{m})$ & $a$ \\
\hline Gandhi and Riazi [57] & 4 & 42 & 6.9 & 1.4 & $/$ \\
Chahat et al. (wrist/forearm) [60] & 8.35 & 28.85 & 7.13 & 0.5 & 0.064 \\
Chahat et al. (palm) [60] & 5.29 & 22.69 & 10.08 & 0.5 & 0.258 \\
Alekseev and Ziskin (forearm) [53] & 4 & 36.4 & 6.9 & 1.4 & $/$ \\
Alekseev and Ziskin (palm) [53] & 4.52 & 31.7 & 6.9 & 1.4 & $/$ \\
\hline
\end{tabular}




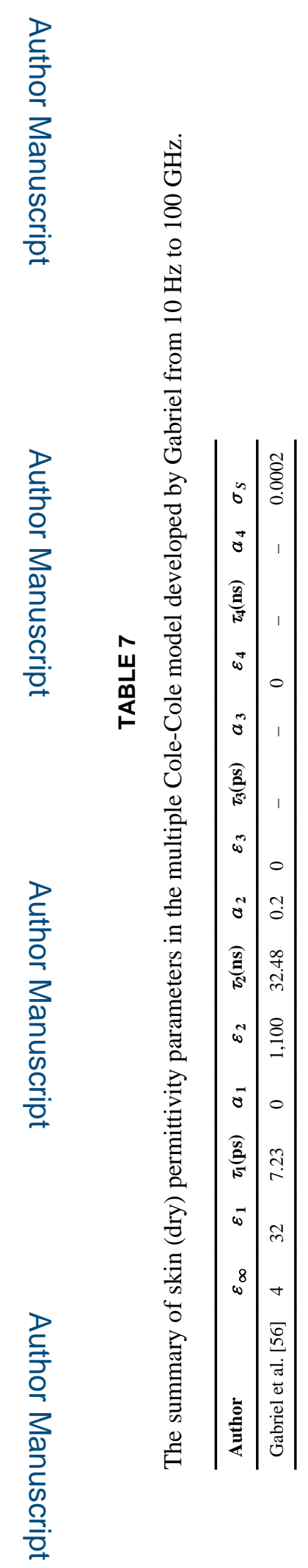




\section{TABLE 8}

The adopted relative permittivity and conductivity in the three-layer tissue model.

\begin{tabular}{lllllll}
\hline $\boldsymbol{f}(\mathbf{G H z})$ & Skin & & SAT & \multicolumn{3}{c}{ Muscle } \\
\hline & $\varepsilon_{r}$ & $\sigma$ & $\varepsilon_{r}$ & $\sigma$ & $\varepsilon_{r}$ & $\sigma$ \\
40 & 11.69 & 31.78 & 5.21 & 6.58 & 18.24 & 43.13 \\
60 & 7.98 & 36.38 & 4.4 & 8.39 & 12.86 & 52.8 \\
80 & 6.4 & 38.38 & 3.95 & 9.66 & 10.17 & 58.58 \\
100 & 5.6 & 39.42 & 3.67 & 10.63 & 8.63 & 62.47 \\
\hline
\end{tabular}




\section{TABLE 9}

The adopted mass density, thermal constant, and tissue thickness in the three-layer tissue model.

\begin{tabular}{lllll}
\hline & Skin & SAT & Muscle & Blood \\
\hline$\rho\left(\mathrm{kg} / \mathrm{m}^{3}\right)$ & 1,109 & 911 & 1,090 & 1,050 \\
$\mathrm{c}\left(\mathrm{J} / \mathrm{kg} /{ }^{\circ} \mathrm{C}\right)$ & 3,391 & 2,348 & 3,421 & 3,617 \\
$\mathrm{k}\left(\mathrm{W} / \mathrm{m} /{ }^{\circ} \mathrm{C}\right)$ & 0.37 & 0.21 & 0.49 & 0.52 \\
$\mathrm{w}(\mathrm{mL} / \mathrm{kg} / \mathrm{min})$ & 106 & 33 & 37 & 10,000 \\
$Q_{m}\left(\mathrm{~W} / \mathrm{m}^{3}\right)[72]$ & 1,620 & 300 & 480 & 0 \\
Tissue thickness $(\mathrm{mm})$ & 1 & 3 & 31 & $/$ \\
\hline
\end{tabular}

